\title{
The Timing of Upper-Layer Neurogenesis Is Conferred by Sequential Derepression and Negative Feedback from Deep-Layer Neurons
}

\author{
Kenichi Toma, ${ }^{1,2}$ Takuma Kumamoto, ${ }^{1}$ and Carina Hanashima ${ }^{1,2}$ \\ ${ }^{1}$ Laboratory for Neocortical Development, RIKEN Center for Developmental Biology, Kobe 650-0047, Japan, and 2Department of Biology, Graduate School \\ of Science, Kobe University, Kobe 657-8501, Japan
}

\begin{abstract}
The prevailing view of upper-layer (UL) neurogenesis in the cerebral cortex is that progenitor cells undergo successive rounds of asymmetric cell division that restrict the competence and production of UL neurons later in development. However, the recent discovery of UL fate-committed early progenitors raises an alternative perspective concerning their ontogeny. To investigate the emergence of UL progenitors, we manipulated the timing and extent of cortical neurogenesis in vivo in mice. We demonstrated that UL competence is tightly linked to deep-layer (DL) neurogenesis and that this sequence is determined primarily through derepression of Fezf2 by Foxg1 within a closed transcriptional cascade. We further demonstrated that the sequential acquisition of UL competence requires negative feedback, which is propagated from postmitotic DL neurons. Thus, neocortical progenitors integrate intrinsic and extrinsic cues to generate UL neurons through a system that controls the sequence of DL and UL neurogenesis and to scale the production of intracortical projection neurons based on the availability of their subcortical projection neuron counterparts during cortical development and evolution.
\end{abstract}

Key words: cell fate; evolution; layer projection neuron; neocortex; neurogenesis; transcription factor

\section{Introduction}

Upper-layer (UL) projection neurons in the cerebral cortex establish interhemispheric synaptic connections and mediate higher-order information processing through bilateral cortical information integration. Complex cognitive and associative behaviors expand with the increased number and diversity of these unique glutamatergic subtypes in mammalian vertebrates (Aboitiz and Montiel, 2003; Schoenemann et al., 2005). Until recently, the prevailing view concerning UL neurogenesis was that neural stem cells, known as radial glial cells (RGCs), undergo successive rounds of asymmetric cell division to produce the principal layer-specific subtypes [preplate, deep-layer (DL), and UL neurons] in a fixed order determined by temporal changes in cell competence (Frantz and McConnell, 1996; Desai and McConnell, 2000; Yu et al., 2009). However, recent studies have dem-

\footnotetext{
Received June 8, 2014; revised Aug. 1, 2014; accepted Aug. 22, 2014.

Author contributions: K.T. and C.H. designed research; K.T., T.K., and C.H. performed research; K.T., T.K., and C.H. analyzed data; K.T., T.K., and C.H. wrote the paper.

This work was supported by a Grant-in-Aid for Scientific Research on Innovative Areas "Neural Diversity and Neocortical Organization" awarded by the Ministry of Education, Culture, Sports, Science, and Technology of Japan (C.H.). The imaging studies were supported by the CDB Imaging Facility. We thank the members of the Hanashima laboratory for insightful comments and discussions. We also thank D. Anderson for providing the Neurog $2^{\text {CreER }}$ mice, G. Fishell for providing the Nestin-CreER mice, Y. Sasai for the Foxg1 antibodies, V. Tarabykin for the Satb2 antibodies, C. Stiles for the Olig2 antibodies, and R. Oda and C. Kumamoto for technical assistance.

Correspondence should be addressed to Carina Hanashima, Laboratory for Neocortical Development, RIKEN Center for Developmental Biology, 2-2-3 Minatojima-minamimachi, Chuo-ku, Kobe 650-0047, Japan. E-mail: hanashima@cdb.riken.jp.

DOI:10.1523/JNEUROSCI.2334-14.2014

Copyright $\odot 2014$ the authors $\quad 0270-6474 / 14 / 3413259-18 \$ 15.00 / 0$
}

onstrated the early segregation of progenitors dedicated to producing UL neurons (Franco et al., 2012). Thus, the emergence of UL progenitors and the regulation of UL neuron differentiation timing remain open questions (Guo et al., 2013).

Disproportionate expansion of neocortical surface area is one significant feature of neocortical development and evolution. Recent studies have shown that expansion in cortical neuron numbers relies on the acquisition of novel progenitor types, such as outer RGCs (Hansen et al., 2010). In a broader evolutionary context, UL neurogenesis regulation requires a developmental process that balances the production of newer UL with older DL neurons (Striedter, 2005; Abdel-Mannan et al., 2008). Consequently, the mechanisms involved must use a system adaptable to increases in cortical size, gestational period, cell cycle, and division modes during mammalian evolution (Fietz and Huttner, 2011; Lui et al., 2011).

Notably, the layer-specific subtype production order can be partially recapitulated in both mouse- and human-derived cortical cells in vitro as follows: Reelin-expressing $\left(\right.$ Reelin $\left.^{+}\right)$preplate cells are generated, followed by the production of Ctip2 ${ }^{+} \mathrm{DL}$ neurons, and finally, Satb $2^{+}$and Cux $1^{+}$UL neurons (Shen et al., 2006; Eiraku et al., 2008; Gaspard et al., 2008; Shi et al., 2012). However, in mouse embryonic stem cell (ESC)-derived cortical cells, $\mathrm{Cux} 1^{+}$and Satb2 ${ }^{+}$UL neurons are underrepresented compared with observed cell proportions in vivo, and the UL neuron number is influenced by culture conditions (i.e., low-density vs aggregate culture; Eiraku et al., 2008; Gaspard et al., 2008). Lowdensity culture conditions are also insufficient to effectively in- 
duce UL neurons in human ESCs and induced pluripotent stem cells (Espuny-Camacho et al., 2013; Kadoshima et al., 2013). These observations suggest that the full complement of UL neuron production may require progenitor cells to integrate intrinsic and extrinsic cues to enable their differentiation.

To test this hypothesis, we manipulated the timing and extent of cortical neurogenesis in vivo. We demonstrated that UL competence is tightly linked to DL neurogenesis, and this sequence is determined primarily through derepression of DL identity by Foxg1. Furthermore, the sequential acquisition of UL competence requires negative feedback propagated from postmitotic DL neurons. Our studies revealed that neocortical progenitors integrate intrinsic and extrinsic cues to generate UL neurons, a system that scales intracortical projection neuron production based on the availability of their subcortical projection neuron counterparts during development and evolution.

\section{Materials and Methods}

Mice. Foxg1 $1^{\text {tetOFoxgl } 1}$ conditional mice were generated by crossing Foxg $1^{\text {tTA/+ }}$ mice with Foxg1 ${ }^{\text {lacZ/+}}$; tetOFoxg1-IRESlac $Z$ double-heterozygous mice (Kumamoto et al., 2013). Foxg $1^{\text {tTA/+ }}$ heterozygous littermates were used as controls. Foxg1 constitutive knock-out mice (Foxg1 lacZ/lacZ) were obtained by intercrossing Foxg1 $1^{\text {lac } Z /+}$ heterozygotes (Xuan et al., 1995). To perform a lineage analysis of Foxg1-induced cells in Foxgl ${ }^{-1-}$ mice, we generated Foxg1 ${ }^{-/-} ;$Rosa $26^{\text {loxp-stop-loxp-YFP/+ }}$ mice by crossing Foxg $1^{\text {LacZ/+ }}$ heterozygotes with Foxg $1^{\text {tTA/+ }}$;Rosa $26^{\text {loxp-stop-loxp-YFP/+ }}$ reporter mice (Srinivas et al., 2001). For neuronal ablation of DL cells, Neurog $2^{\text {CreER/+ }}$ mice (Zirlinger et al., 2002) were crossed with the Rosa26 loxp-stop-loxp-dta/+ mouse line (Ivanova et al., 2005). To evaluate Cre recombination in vivo, we crossed Neurog 2 CreER/+ or Nestin ${ }^{\mathrm{CreER} /+}$ mice (Balordi and Fishell, 2007) with Rosa26 $6^{\text {loxp-stop-loxp-lacZ/+ }}$ mice (Soriano 1999) and Neurog $2^{\text {CreER/+ }}$ with Rosa26 $6^{\text {loxp-stop-loxp-YFP/+ }}$ and Rosa26 ${ }^{\text {CAG-loxp-stop-loxp-tdTomato/+ }}$ mice (Ai9 reporter; Madisen et al., 2010). Noon on the day of vaginal plug detection was designated embryonic day 0.5 (E0.5). Male and female mice were used in the experiments. The animals were housed in the Animal Housing Facility of the RIKEN Center for Developmental Biology (Kobe, Japan), and the experiments were conducted under the institutional guidelines.

Doxycycline and tamoxifen administration. To manipulate Foxg1 expression in vivo, pregnant female mice obtained from Foxgl ${ }^{\text {lacZI+ }}$; tetOFoxg1-IRESlacZ and Foxg $1^{\text {tTA/+ }}$ mice crosses were administered $250 \mu \mathrm{l}$ of $8 \mu \mathrm{g} / \mathrm{ml}$ doxycycline (Dox) in 5\% sucrose from E9.5 until the designated developmental day. The mice were maintained on $2 \mu \mathrm{g} / \mathrm{ml}$ Dox administered in drinking water that contained 5\% sucrose. For Foxg1 induction, Dox water bottles were replaced with normal drinking water at noon on E14.5, E15.5, or E16.5. Embryos were harvested at the indicated stages. To suppress Foxg1 expression in vivo, pregnant female mice obtained from Foxg1 ${ }^{\text {lacZ/+ }}$; tetOFoxg1-IRESlacZ and Foxg1 ${ }^{\text {tTA/+ }}$ mice were administered $250 \mu \mathrm{l}$ of $800 \mu \mathrm{g} / \mathrm{ml}$ Dox in $5 \%$ sucrose from E9.5 until the designated developmental day. The mice were maintained under $200 \mu \mathrm{g} / \mathrm{ml}$ Dox in drinking water that contained 5\% sucrose. For constitutive suppression of Foxg1 expression, Dox solution bottles were changed every other day.

To induce Cre-mediated recombination in Rosa26 reporter lines, pregnant dams were orally administered $10 \mathrm{mg} / 40 \mathrm{~g}$ body weight of tamoxifen (Sigma), which was dissolved in $20 \mathrm{mg} / \mathrm{ml}$ corn oil (Sigma), using silicon-protected needles at the indicated stages. For the DL ablation experiments, tamoxifen was administered to pregnant dams at noon on E11.5, E12.5, and E13.5 (once per day, three times total).

Immunohistochemistry. Brains from the indicated developmental stage animals were dissected and fixed in 1 or $4 \%$ paraformaldehyde (PFA) for $1 \mathrm{~h}$ at $4^{\circ} \mathrm{C}$. For E16.5 and older stages, the brains were perfused with PBS and subsequently with 1 or $4 \%$ PFA before fixation. After 30\% sucrose replacement overnight at $4^{\circ} \mathrm{C}$, the fixed brains were embedded in OCT compounds, and $12 \mu \mathrm{m}$ (all experiments except the ones shown in Fig. $7 B, C$ ) or $50 \mu \mathrm{m}$ (see Fig. $7 \mathrm{~B}, C$ ) frozen sections were cut using a cryostat (Microm HM550; Carl Zeiss). The following antibodies were used for immunostaining: rat anti-Ctip2 (1:1000; Abcam), rabbit anti-Zfpm2 (FOG2; 1:100; Santa Cruz Biotechnology), goat anti-SOX2 (Y-17 1:250; Santa Cruz Biotechnology), rabbit anti-Tbr1 (1:500; Abcam), chicken anti-Tbr1 (1:500; Millipore), mouse anti-Satb2 (1:100; Abcam), rabbit anti-Satb2 (1:1000; a gift from V. Tarabykin, Institute for Cell Biology and Neurobiology, Center for Anatomy, Charite, Berlin, Germany), rabbit anti-Cux1 (CDP1; 1:100; Santa Cruz Biotechnology), rabbit antiOlig2 (1:20,000; a gift from C. Stiles, Dana-Farber Cancer Institute, Boston, MA), chicken anti-GFP (1:500; Abcam), rabbit anti-RFP (1:500; Abcam), goat anti-Foxg1 (N-15; 1:200; Santa Cruz Biotechnology), rabbit anti-Foxg1 (1:500; StemCulture), rabbit anti-Foxg1 (1:1000; Abcam), rabbit anti-Foxg1 (1:1000; a gift from Y. Sasai), mouse anti-Tuj1 (1:1000; Covance), rabbit anti-Tbr2/Eomes (1:400; Abcam), mouse anti-Ki67 (1: 500; BD Pharmingen), and rabbit anti-Fezf2 (1:100; IBL). For Satb2 (Abcam) detection, the sections were incubated at $105^{\circ} \mathrm{C}$ in sodium citrate buffer with $0.05 \%$ Tween $20, \mathrm{pH} 6.0$, for $10 \mathrm{~min}$ before incubation with the primary antibody. For Ctip2 and Zfpm 2 double immunohistochemistry, the sections were incubated at $70^{\circ} \mathrm{C}$ in Histo VT One (Nacalai Tesque) for $20 \mathrm{~min}$ before incubation with the primary antibody. The primary antibodies were detected with Alexa Fluor-conjugated secondary antibodies (Invitrogen and Jackson ImmunoResearch). The nuclei were stained with 4',6-diamidino-2-phenylindole dihydrochloride (DAPI), and the sections were mounted on slides (Matsunami glass) using SlowFade antifade reagents (Invitrogen). Data acquisition was performed using an Axio Imager Z1 fluorescence microscope (Carl Zeiss; all experiments except the experiments shown in Fig. $3 B-G$ ) or an LSM710 confocal microscope (Carl Zeiss; see Fig. 3B-G).

For Tbr 1 and Foxg1 immunohistochemistry, multiple antibodies were assessed for protein detection: Tbr1, rabbit anti-Tbr1 (Abcam), and chicken anti-Tbr1 (Millipore); and Foxg1, goat anti-Foxg1 (Santa Cruz Biotechnology), rabbit anti-Foxg1 (Abcam), rabbit anti-Foxg1 (StemCulture; previous and current antibody Lots), and rabbit anti-Foxg1 (a gift of Y. Sasai, RIKEN Center for Developmental Biology, Kobe, Japan). Immunohistochemistry comparing the two Tbr1 antibodies revealed similar expression patterns, except that rabbit anti-Tbrl antibody (Abcam) showed slightly higher sensitivity to Tbrl protein than chicken anti-Tbr1 antibody (Millipore), as observed in the differences between Figure $6 C^{\prime}, D^{\prime}$ (rabbit anti-Tbr1 antibody) and Figure $6 E^{\prime \prime \prime}, F^{\prime \prime \prime}$ (chicken anti-Tbrl antibody). The following Tbrl antibodies were used to allow double immunohistochemistry in combination with other antibodies: rabbit anti-Tbr1 (Abcam; see Figs. 4, 5, 6C-D'" ) and chicken anti-Tbr1 (Millipore; see Fig. $\left.6 E-F^{\prime \prime \prime \prime \prime}, G-G^{\prime \prime \prime \prime}\right)$. Comparison between the different Foxg1 antibodies revealed similar expression patterns, but the detection levels varied between the antibodies tested. All antibodies detected Foxg1 protein within the cortical plate (CP), and among these, goat anti-Foxg1 antibody (Santa Cruz Biotechnology) and rabbit anti-Foxg1 antibody (StemCulture; previous antibody Lot) showed the highest sensitivity. Within the ventricular zone (VZ), rabbit anti-Foxg1 antibody (StemCulture; previous antibody Lot) showed the highest detection levels, and rabbit anti-Foxg1 antibody (StemCulture; new antibody Lot), rabbit anti-Foxg1 antibody (a gift from Y. Sasai), and goat anti-Foxg1 antibody (Santa Cruz Biotechnology) revealed weaker detection levels. Immunohistochemistry using rabbit anti-Foxg1 antibody (Abcam) revealed very low detection levels in the VZ. The following Foxg1 antibodies were used to allow double immunohistochemistry in combination with other antibodies: rabbit anti-Foxg1 (StemCulture; Figs. 2, 3) and goat anti-Foxg1 (Santa Cruz Biotechnology; Fig. 4).

$\beta$-Galactosidase ( $\beta$-gal) histochemistry was performed as described previously (Hanashima et al., 2002). $\beta$-gal-stained sections were counterstained with nuclear Fast Red (Merck).

Neuronal birthdating. Pregnant dams were administered a single pulse of BrdU and a single pulse of EdU (both $50 \mathrm{mg} / \mathrm{kg}$ body weight) by intraperitoneal injection at the indicated stages. Embryos were harvested at E18.5, perfused, and fixed in 4\% PFA for $1 \mathrm{~h}$. For BrdU double immunohistochemistry, BrdU immunostaining was performed after the detection of the first antigen with the indicated antibodies. The sections were sequentially treated with $1 \mathrm{~N} \mathrm{HCl}$ at $55^{\circ} \mathrm{C}(10 \mathrm{~min}), 1.25 \mu \mathrm{g} / \mathrm{ml}$ proteinase $\mathrm{K}$ (Roche) at $37^{\circ} \mathrm{C}(10 \mathrm{~min})$, and $4 \% \mathrm{PFA}$ (10 min; postfixation) and then washed in PBS. The tissue sections were incubated overnight at $4^{\circ} \mathrm{C}$ with 
mouse anti-BrdU antibody (1:100; Santa Cruz Biotechnology) or with rat anti-BrdU antibody (1:100, AbD Serotec). For EdU double immunohistochemistry, EdU was visualized using a Click-iT EdU kit (Invitrogen) after the detection of the first antigen. To obtain accurate birthdating, the nuclei that contained full BrdU/EdU content were quantified in Figure $1 A M$. This eliminated cells that underwent more than one cell division after BrdU or EdU incorporation.

Plasmids. The Foxg1 expression vector (pCAGGS-Foxg1) was constructed as follows. The 1-2070 fragment from the Foxg1 cDNA clone mN3 (Tao and Lai, 1992) was PCR amplified, blunt-end treated, and inserted into the XhoI site of the pCAGGS vector (Niwa et al., 1991). For the luciferase reporter assays, a Tbr1 5' flanking fragment (GenBank accession number AB032374) was amplified by PCR using genomic DNA from E14.5 CD1 mice and cloned into the EcoRV site of the pGL4.10[luc2] vector (Promega) using an In-Fusion cloning kit (Takara). The following oligonucleotide sequences were used for construction of the plasmids: Foxg1 forward, 5'-ATGCTGGACATGG GAGATAGG-3'; Foxg1, reverse, 5' -TTATCATTTACAATGCAAATG3'; Tbr1-5' forward, 5'-GCTAGCCTCGAGGATGGATCCCAAAC GTCATTTG-3'; and Tbr $1-5^{\prime}$ reverse, 5'-AGGCCAGATCTTG ATAGCTCTAGAACCTGAACGC-3'.

In utero electroporation. Pregnant dams were deeply anesthetized via an intraperitoneal injection of Nembutal sodium solution (Lundbeck), and the uterine horns were exposed. Electroporation was performed using a CUY21EDIT electroporator (Nepagene). To visualize the injection site, $0.1 \%$ Fast Green (Wako) was added to the DNA solution. One microliter of DNA solution was introduced by trans-utero injections into the lateral ventricles of the recipient embryos using 0.75 -mm-innerdiameter pulled capillary tubing (Fredrick Haer), and 50-ms-on, 950ms-off, 33-V square pulses were delivered four times using a platinum electrode (CUY650P5; Nepagene). After electroporation, the abdominal walls and skin of the pregnant dams were sutured, and the dams were maintained on a $37^{\circ} \mathrm{C}$ heating plate until recovery. The DNA concentrations used were as follows: pCAGGS-GFP, $1 \mu \mathrm{g} / \mu \mathrm{l}$; pCAGGS-Foxg1, 4 $\mu \mathrm{g} / \mu \mathrm{l}$; and pCAGGS-Cre, $1 \mu \mathrm{g} / \mu \mathrm{l}$.

Transcriptome analysis. To identify the transcriptional network responsible for layer subtype specification downstream of Foxg1, we used previous datasets in which the temporal cohorts of $\mathrm{CD}_{133^{+}}$cells after Foxg1 induction in vivo were FACS sorted and subject to Affymetrix high-density oligonucleotide arrays for Mus musculus (Mouse Genome 4302.0 ), which contained 45,038 probes (Kumamoto et al., 2013). To identify differentially expressed genes, the expression values were summarized using the robust multi-array average method, and one-way ANOVAs with post hoc tests were performed for each probe set. Multiple comparisons were corrected using false discovery rates (FDRs); an FDR of $<0.05$ was chosen as significant (i.e., significantly differentially expressed genes). A supervised clustering analysis, for which 30 template binary patterns with repeated permutations $(0,1$; length $=5$, and not $0,0,0,0,0$ or $1,1,1,1,1)$ were prepared, was used for classification. For each probe set in the significantly differentially expressed gene set, Pearson's correlation coefficients between the mean expression values in the five experimental conditions, (E14.5, E15.0, E15.5, E16.5, and E15.5 Dox +$)=(A, B, C, D$, and $E)$, and every binary pattern were calculated, and the most highly correlated pattern was chosen as the expression pattern. The probe sets in which $(\mathrm{A}, \mathrm{B}, \mathrm{C}, \mathrm{D}, \mathrm{E})=(1,0,0,0,1),(1,1,0,0,1)$, $(1,1,1,0,1)$ and $(0,1,1,1,0),(0,0,1,1,0),(0,0,0,1,0)$ were categorized as significantly downregulated and upregulated group sets, respectively. Genes that corresponded to the transcripts of these six groups were considered Foxg1-responsive genes. These genes were depicted and presented as a heat map that represents the relative fold change in gene expression between E16.5 Foxg1 $1^{\text {tetOFoxg1 }}$ cortex/E14.5 Foxg1 ${ }^{\text {tetOFoxg1 }}$ cortex (see Fig. $4 C)$.

Luciferase reporter assay. A neuroblastoma cell line (Neuro2a; Japanese Collection of Research Bioresources Cell Bank number IFO50081) was cultured in medium that contained 50\% DMEM and 50\% Opti-MEM I (Invitrogen) supplemented with 10\% fetal bovine serum. For luciferase assays, $9 \times 10^{3}$ cells were plated in 96-well plates and transfected the next day with a firefly luciferase reporter (pGL4.10, 100 ng/well; Promega), a Renilla luciferase vector (pGL4.74, 100 ng/well; Promega) to normalize transfection efficiency, and a pCAGGS-Foxg1 vector (500 ng/well). The transfection was performed using Fugene6 transfection reagent according to the protocol of the manufacturer (Promega). The cells were harvested $48 \mathrm{~h}$ after transfection and processed using the Dual-Glo Luciferase Assay System (Promega). Luciferase activity was measured using a 1420ARVOsx-1 luminometer (PerkinElmer Life and Analytical Sciences). The data were obtained in quadruplicate from four independent experiments.

Quantification. For quantifying neurons in DL-ablated and control cortices, the total number of cells that expressed the indicated markers per $100 \mu \mathrm{m}$ cortical strip from the dorsolateral cortex were counted, with the exception of the total cell counts in Figure $8 I-X$, which were obtained from $260 \mu \mathrm{m}$ cortical strips.

Statistical analysis. The quantitative data are presented as the mean \pm SEM from representative experiments $(n \geq 3)$. For all statistical analyses, the data were evaluated using Student's $t$ test. $p$ values $<0.05$ were considered significant.

\section{Results}

The sequence of DL and UL neurogenesis is fixed regardless of the timing of projection neuron induction in vivo

To investigate the emergence of UL neurons, we first assessed the temporal window in which UL projection neurons can be induced in vivo. We established previously a transgenic mouse line in which the onset of neocortical projection neuron production can be synchronously manipulated using the expression of a forkhead transcription factor (TF), Foxg1 (Kumamoto et al., 2013). In this mouse line, endogenous Foxg1 sequences are replaced with a lac $Z$ coding sequence and a tet-transactivator (tTA) coding sequence (Foxg1 $1^{\text {tTA/lacZ }}$ knock-in null mice), which drives Foxg1 expression under the regulation of the tet $O$ minimal promoter of an independent tetOFoxg1 transgenic allele (Foxg $1^{\text {tetOFoxg1 }}$ mice; Fig. 1A). Foxg1 expression is suppressed in the presence of Dox, whereas Dox removal results in Foxg1 induction (Tet-off system). In Foxg $1^{\text {tetOFoxgl }}$ mice, we demonstrated previously that the delayed Foxg1 induction by Dox withdrawal at E14.5 is sufficient to switch to DL neurogenesis after a prolonged period of earliestborn Reelin ${ }^{+}$Cajal-Retzius (CR) neuron production (Kumamoto et al., 2013). Therefore, we induced Foxg1 at progressively later stages of corticogenesis, at E14.5, E15.5 and E16.5, to assess the temporal window in which UL projection neurons can be induced in vivo (Fig. 1B). To circumvent the early developmental defects that result from the loss of Foxg1, Dox was administered starting at E9.5 (Fig. 1B), when the size differences between the Foxg1 heterozygote and homozygote cortices are minimal (Xuan et al., 1995). To label the temporal cohorts of neurons born after Foxg1 induction, we injected pulses of BrdU and EdU at a $24 \mathrm{~h}$ interval and monitored layer-specific subtype production at E18.5 (Fig. 1B). To assess the relative proportions of neurons that were produced at each time point, BrdU- or EdU-labeled cells that were colabeled with Ctip2 (DL neuron marker) or Satb2 or Brn2 (UL neuron markers) of the total BrdU- or EdU-labeled cells were quantified per $100 \mu \mathrm{m}$ strip of dorsolateral cortices through the $\mathrm{VZ}$ to the marginal zone (MZ; Fig. $1 C-A M)$. To obtain accurate birthdating, the nuclei that contained full BrdU/ EdU content were quantified to eliminate cells that underwent more than one cell division after BrdU/EdU incorporation (see Materials and Methods). Consistent with previous results ( $\mathrm{Ku}-$ mamoto et al., 2013), when Foxg1 was induced at E14.5, we observed a shift in the production of Ctip $2^{+}$DL neurons that were colabeled primarily with BrdU (Foxg1 $1^{\text {tetOFoxg1 }}$ cortex, $72.6 \pm$ 2.6\% Ctip ${ }^{+} / \mathrm{E} 14.5 \mathrm{BrdU}^{+}$cells; control cortex, $5.9 \pm 0.7 \%$ Ctip2 ${ }^{+} / \mathrm{E} 14.5 \mathrm{BrdU}^{+}$cells; Fig. $\left.1 C-D^{\prime}, I-J^{\prime}, A M\right)$. Additional analyses that used sequential E14.5 BrdU and E15.5 EdU labeling 
A Foxg1 $1^{\text {tetoFoxg1 }}$ mice (Foxg1 $1^{\text {tTAlacz }}$;etOFoxg1 mice)

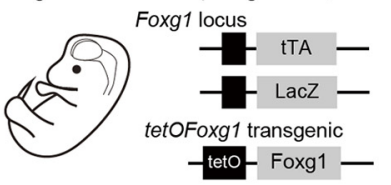

+ Doxycycline (2ug/g)

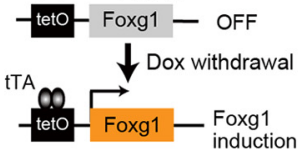

B



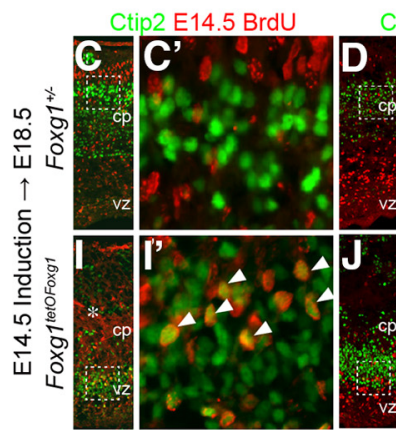


$\mathbf{A C}$

AM
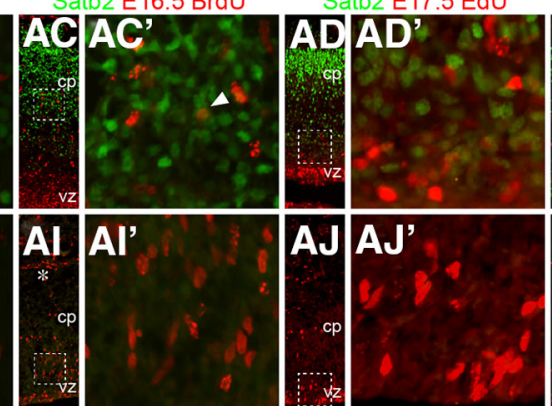

Brn2 E16.5 BrdL

$\mathbf{A F}$
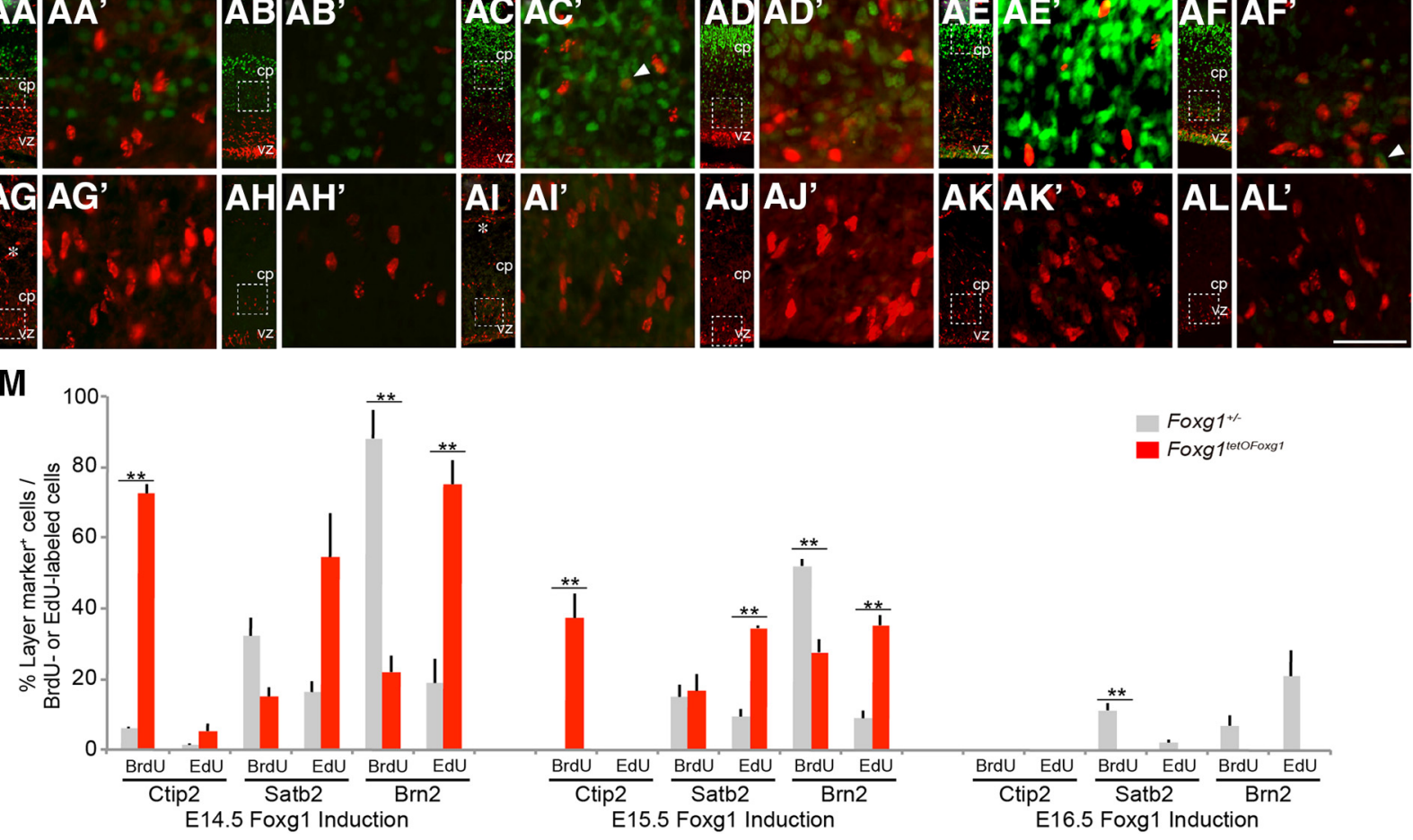

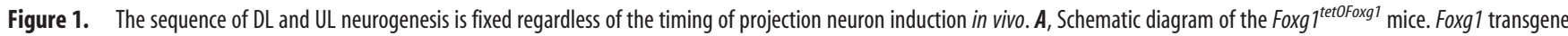
expression was initially repressed by Dox administration, and Foxg1 expression was induced by Dox withdrawal. $\boldsymbol{B}$, Experimental design. After Dox administration at E9.5, Foxg1 was induced by Dox withdrawal at the indicated embryonic stages, and the dams were subsequently administered pulses of BrdU (red arrowheads) and EdU (blue arrowheads) at the specified time points. All embryos


$\boldsymbol{A} \boldsymbol{A}^{\prime}-\boldsymbol{A} \boldsymbol{L}^{\prime}$, Enlarged views of the boxed regions shown in $\boldsymbol{C}-\mathbf{Z}$ and $\boldsymbol{A} \boldsymbol{A}-\boldsymbol{A} \boldsymbol{L}$. The arrowheads indicate cells that were double labeled with respective markers (Ctip2, Satb2, or Brn2 with BrdU or EdU). Asterisks indicate nonspecific background staining of blood vessels by mouse monoclonal antibody. $A M$, Quantitative analysis of the percentage of BrdU ${ }^{+}$and EdU ${ }^{+}$cells that expressed Ctip2, Satb2, or Brn2 in the indicated genotypes. Cells in the entire $100 \mu \mathrm{m}$ radial strips (as represented in $\boldsymbol{C}-\mathbf{Z}, \boldsymbol{A} \boldsymbol{A}-\boldsymbol{A L}$ ) from the dorsolateral cortices, including VZ cells, were counted. The results are expressed as the mean \pm SEM. ${ }^{* *} p<0.01$. Scale bars: $\boldsymbol{C}^{\prime}-\boldsymbol{Z}^{\prime}, \boldsymbol{A A}^{\prime}-\boldsymbol{A \boldsymbol { L } ^ { \prime } ,}, 20 \mu \mathrm{m}$. 
indicated that Ctip2 ${ }^{+}$neuron production preceded Satb ${ }^{+}$or Brn $2{ }^{+}$UL neuron generation (Foxg1 ${ }^{\text {tetOFoxg1 }}$ cortex, $22.1 \pm 4.5 \%$ $\mathrm{Brn}^{+} / \mathrm{E} 14.5 \mathrm{BrdU}^{+}$cells, $75.2 \pm 6.8 \% \mathrm{Brn}^{+} / \mathrm{E} 15.5 \mathrm{EdU}^{+}$ cells, $15.1 \pm 2.5 \% \mathrm{Satb}^{+} / \mathrm{E} 14.5 \mathrm{BrdU}^{+}$cells, and $54.6 \pm 12.6 \%$ Satb ${ }^{+} / \mathrm{E} 15.5 \mathrm{EdU}^{+}$cells; control cortex, $88.1 \pm 8.1 \% \mathrm{Brn} 2^{+} /$ E14.5 BrdU ${ }^{+}$cells, $18.8 \pm 7.1 \% \mathrm{Brn}^{+} / \mathrm{E}^{2} 15.5 \mathrm{EdU}^{+}$cells, $32.0 \pm$ $5.3 \%$ Satb ${ }^{+} / \mathrm{E} 14.5 \mathrm{BrdU}^{+}$cells, and $16.2 \pm 3.2 \%$ Satb ${ }^{+} / \mathrm{E} 15.5$ $\mathrm{EdU}^{+}$cells; Fig. $\left.1 E-H^{\prime}, K-N^{\prime}, A M\right)$. Notably, although both BrdU- and EdU-labeled cells in the control cortex migrated into the CP (Fig. $1 C-H^{\prime}$ ), the majority of $\mathrm{BrdU}^{+}$and $\mathrm{EdU}^{+}$cells in the Foxg1 $1^{\text {tetOFoxg1 }}$ cortex failed to integrate into the preceding neuronal layer and accumulated beneath the overlying CP. This overlying CP in the Foxg $1^{\text {tetOFoxg1 }}$ cortex consists of supernumerary CR cells that were generated during the period of Foxg1 suppression (data not shown and Kumamoto et al., 2013) and thus resemble the migration termination of projection neurons beneath the $\mathrm{CR}$ cell containing $\mathrm{MZ}$ during normal development (Fig. $1 I-N^{\prime}$ ).

Next, we performed the same analysis in a 1-d-later shifted experiment, in which we induced Foxg1 at E15.5 by Dox removal (Fig. $1 B$, middle row). We determined that E15.5 Foxg1 induction was also sufficient to induce both DL and UL subtypes (Fig. $\left.1 U-Z^{\prime}, A M\right)$. E15.5 BrdU and E16.5 EdU injections revealed that $\mathrm{Satb} 2{ }^{+}$and $\mathrm{Brn} 2{ }^{+}$neurons were also generated later compared with Ctip ${ }^{+}$neurons in these mutants; Ctip ${ }^{+}$DL neurons were predominately generated at E15.5 $37.3 \pm 6.8 \% \mathrm{Ctip}^{+} / \mathrm{E} 15.5$ $\mathrm{BrdU}^{+}$cells and $0 \% \mathrm{Ctip}^{+} / \mathrm{E} 16.5 \mathrm{EdU}^{+}$cells; Fig. $\left.1 U-V^{\prime}, A M\right)$, and Satb $2^{+}$and Brn $2^{+}$cells were generated at E16.5 (16.7 \pm $5.0 \% \mathrm{Satb}^{+} / \mathrm{E} 15.5 \mathrm{BrdU}^{+}$cells, $34.6 \pm 0.6 \% \mathrm{Satb}^{+} / \mathrm{E} 16.5$ $\mathrm{EdU}^{+}$cells, $27.7 \pm 3.6 \% \mathrm{Brn}^{+} / \mathrm{E} 15.5 \mathrm{BrdU}^{+}$cells and $35.4 \pm$ $2.9 \% \mathrm{Brn}^{+} / \mathrm{E} 16.5 \mathrm{EdU}^{+}$cells, respectively; Fig. $\left.1 W-Z^{\prime}, A M\right)$. Together, these results suggested that UL progenitors could not bypass DL competence for their production even at the latest period of corticogenesis. This finding was consistent with the results obtained when we further induced Foxg1 1 d later at E16.5 by Dox removal (Fig. $1 B$, bottom row). We observed that Ctip ${ }^{+}$ cells were not detectable in the cortex (Fig. $1 A G-A H^{\prime}$ ), and Satb ${ }^{+}$and Brn $2^{+}$UL neurons were absent (Fig. $1 A I-A L^{\prime}, A M$ ). The chase period after BrdU and EdU injections (at E16.5 and E17.5, respectively) may not have provided sufficient time for these markers to be turned on in these mice; however, we identified a low proportion of BrdU- or EdU-labeled cells that expressed Satb2 and Brn2 in the control cortex but not in the Foxg1 ${ }^{\text {tetOFoxg1 }}$ cortex (Fig. $1 A C^{\prime}-A F^{\prime}$, arrowheads). These data indicated that these birthdates correspond to the latest period of neurogenesis (Hevner et al., 2003) and to the onset of gliogenesis (Seuntjens et al., 2009) during normal development. The results also suggested that Foxg1 induction is sufficient to initiate sequential DL-UL competence but cannot override gliogenic competence. Consistent with these observations, the contribution of E16.5-born progenitors to Olig2 ${ }^{+}$glial cells was comparable between the Foxg1 $1^{\text {tetOFoxgl }}$ and control cortices $(30.1 \pm 1.5$ and $19.5 \pm 5.9 \%$, respectively; data not shown), which was similar to the result of a previous study (Seuntjens et al., 2009). Collectively, these data demonstrate that cortical progenitors have a restricted competence window in vivo, such that UL competence strictly follows DL competence and is terminated by gliogenic competence.

\section{UL progenitors arise from the Foxg ${ }^{+}$cell lineage}

The conserved sequence of DL and UL competence throughout the corticogenesis period indicates the following two potential, non-mutually exclusive, mechanisms of UL neurogenesis: neo- cortical progenitors use intrinsic cues that induce bias toward DL competence over UL competence and/or feedback signaling from DL neurons is necessary to trigger UL neurogenesis during cortical development. These mechanisms are supported by the observations that DL neurons are generated more efficiently compared with UL neurons in vitro (Espuny-Camacho et al., 2013) and that UL neurons favor high-density aggregate conditions compared with low-density cultures for their induction (Shen et al., 2006; Eiraku et al., 2008; Gaspard et al., 2008; Kadoshima et al., 2013). To test the former mechanistic hypotheses, we induced neocortical projection neurons in a restricted number of cells by electroporating pCAGGS-Foxg1 and pCAGGSGFP constructs into E14.5 Foxg1 constitutive knock-out (Foxg1 ${ }^{-1-}$ ) cortices (Fig. $2 A-D^{\prime \prime}$ ), which lack DL and UL neuron production and exhibit CR cell overproduction (Kumamoto et al., 2013). Consistent with the role of Foxg1 in switching from early CR cells to DL neurogenesis (Kumamoto et al., 2013), Ctip ${ }^{+} \mathrm{DL}$ neurons were induced in the $\mathrm{GFP}^{+}$cells in the pCAGGS-Foxg1 and pCAGGS-GFP-introduced cortex (Fig. 2I). Notably, within this cluster, we also detected Satb2 ${ }^{+}$cells (Fig. $2 J)$ and Brn $2^{+}$cells (Fig. $2 R$ ), which were mostly complementary to Ctip ${ }^{+}$cells (Fig. $2 K, S$ ). However, within Satb2 ${ }^{+}$neurons, GFP was either not expressed in these cells or only expressed at low levels (Fig. $2 L-L^{\prime \prime \prime}$, open arrowheads). We further assessed the expression of Foxg1 protein in Satb ${ }^{+}$cells by double immunohistochemistry of Foxg1 and Satb2 and found that Foxg1 expression was either undetectable in Satb ${ }^{+}$cells (Fig. $2 A B-A B^{\prime \prime}$, open arrowheads) or expressed at very low levels (Fig. $2 A B-A B^{\prime \prime}$, filled arrowheads). This was in contrast to Ctip ${ }^{+}$cells, which generally expressed high levels of Foxg1 protein (Fig. $2 X-X^{\prime \prime}$, filled arrowheads). This result suggested that, during Foxg1 induction, Satb $2{ }^{+}$cells may be generated later within the Foxg $1^{+}$lineage; thus, the GFP and Foxg1 plasmid is diluted through multiple rounds of cell division.

To directly test this hypothesis, we coelectroporated pCAGGS-Foxg1 and pCAGGS-Cre constructs into Foxg1 ${ }^{-/-}$; Rosa $26^{\text {loxp-stop-loxp-YFP/+ }}$ mice to label all progeny of E14.5 Foxg1introduced progenitors and examined the yellow fluorescent protein (YFP) ${ }^{+}$cells at E18.5 (Fig. 3A-G). We identified Satb2 ${ }^{+}$ (Fig. $3 F-F^{\prime \prime}, G$, arrowheads) and Ctip ${ }^{+}$(Fig. $3 D-D^{\prime \prime}, E$, arrowheads) expression in $\mathrm{YFP}^{+}$cells but not in YFP-negative $\left(\mathrm{YFP}^{-}\right)$ cells (Fig. 3D- $D^{\prime}, F-F^{\prime}$ ). Therefore, we defined the emergence of Satb ${ }^{+}$cells as originating from cells with a Foxg1 lineage after the onset of Foxg1 expression. Cell birthdating studies that used consecutive E14.5 BrdU and E15.5 EdU injections (Fig. $3 H$ ) confirmed that Satb2 ${ }^{+}$cell generation followed Ctip ${ }^{+}$cell generation in the same cluster $\left(\mathrm{Ctip} 2^{+} / \mathrm{BrdU}^{+}\right.$cells, $39.4 \pm 1.2 \%$; $\mathrm{Ctip}^{+} / \mathrm{EdU}^{+}$cells, $14.7 \pm 1.8 \%$; Satb ${ }^{+} / \mathrm{BrdU}^{+}$cells, $16.0 \pm$ $1.7 \%$; and Satb2 ${ }^{+} / \mathrm{EdU}^{+}$cells, $36.5 \pm 2.1 \%$; Fig. $\left.3 I-L^{\prime \prime}, M\right)$. Notably, within these restricted neocortical neuron clones, the number of Satb $2^{+}$and Brn2 ${ }^{+}$cells did not exceed the number of Ctip $2{ }^{+}$cells generated in the same cluster (Fig. $2 \mathrm{~K}, S$ and data not shown).

\section{Foxg1 confers the sequence of DL and UL competence through Tbr1 repression within a closed transcriptional cascade}

The Foxg1 lineage studies indicated that the cascade downstream of Foxg1 triggers the sequential competence of DL and UL neuron production. Next, we identified the transcriptional cascade that determines this sequence of layer neurogenesis. Previous genetic studies have indicated that the segregation between the principal layer subtypes of the cerebral cortex is established on a 
A

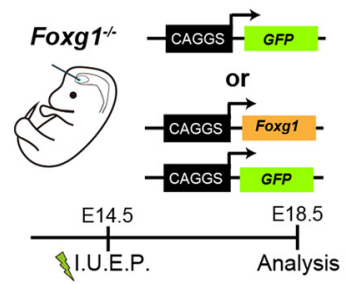

B

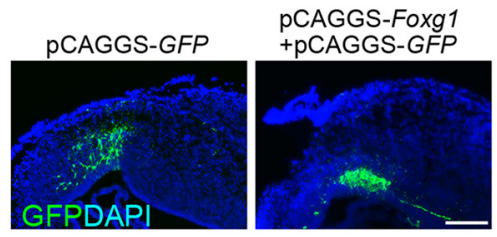

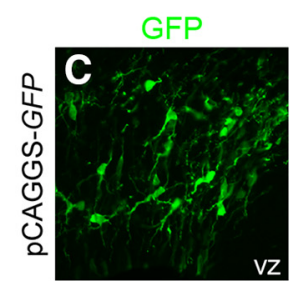
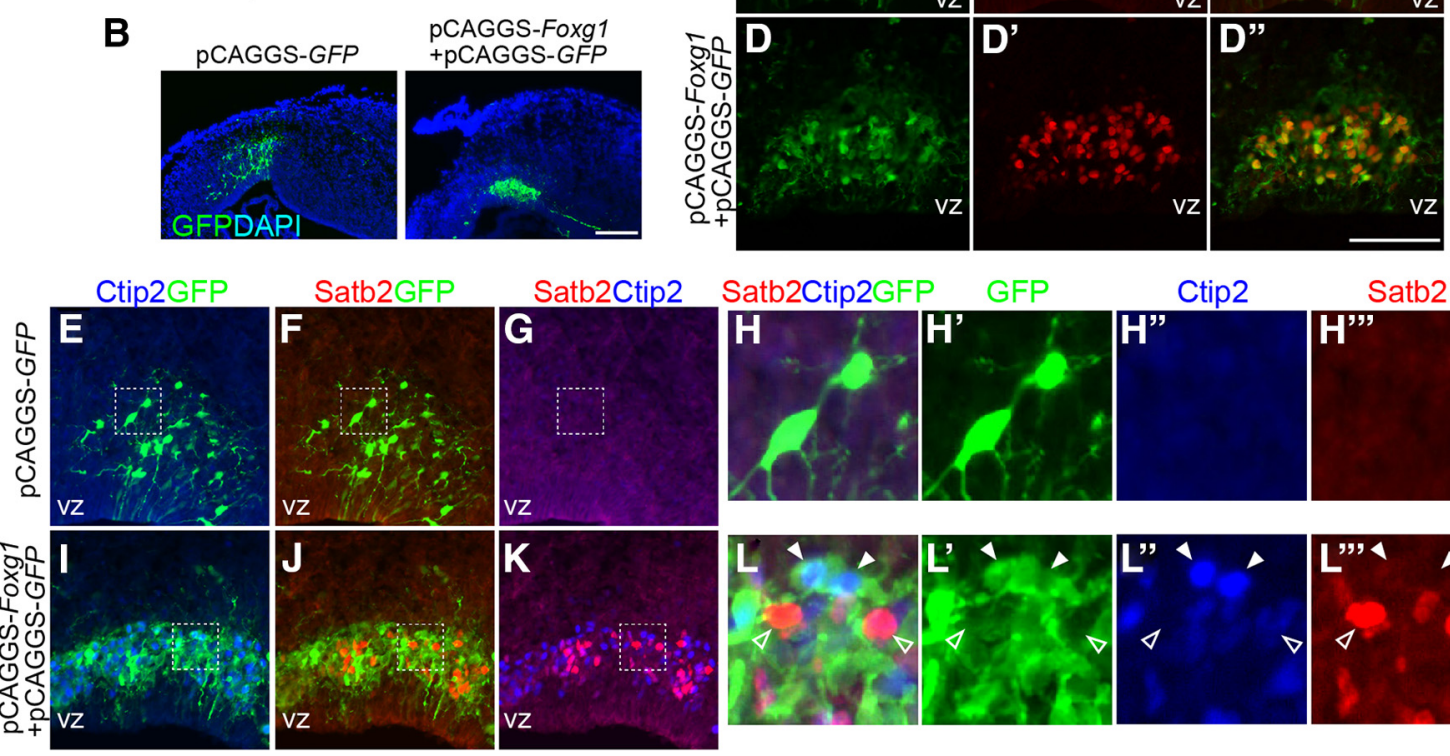

Ctip2
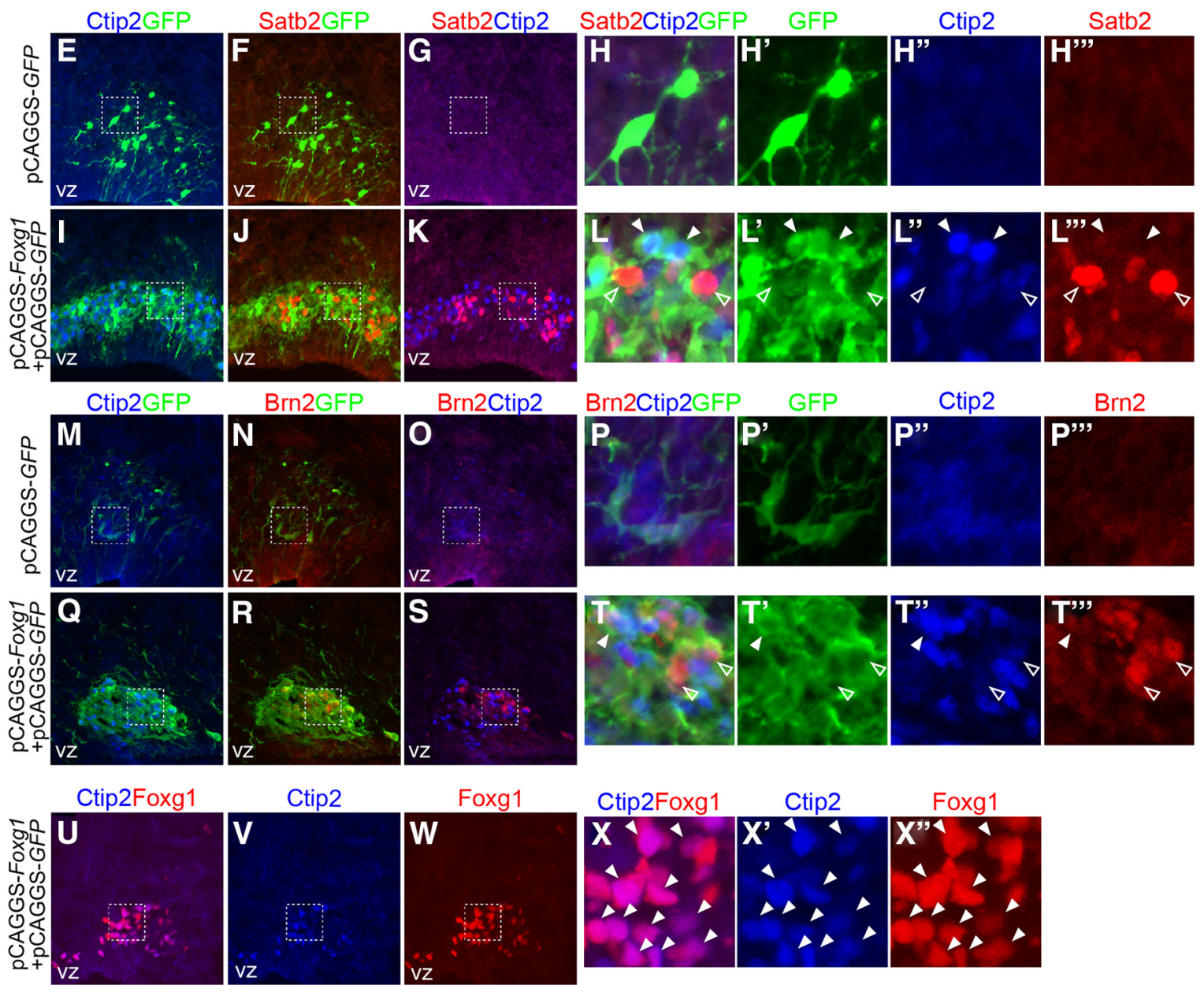

Ctip2


Foxg1
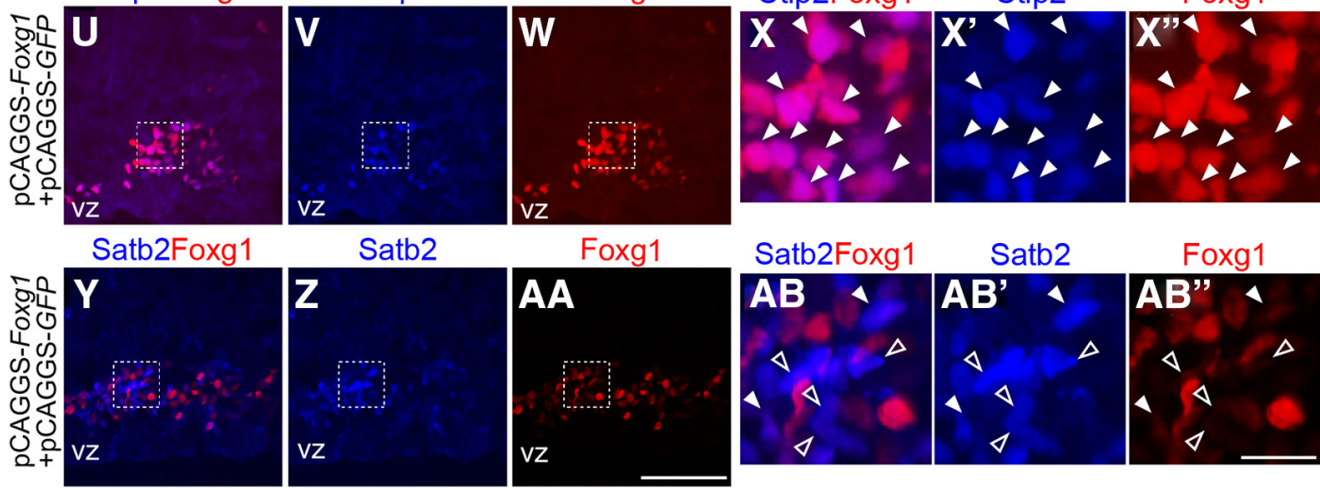

Figure 2. UL neurons are induced in a restricted number of cortical cells. $\boldsymbol{A}$, Experimental design. I.U.E.P., In utero electroporation. Foxg $1^{-/-}$constitutive knock-out mice were used. $\boldsymbol{B}$, Lower-magnification views of the cortex, which indicate representative GFP electroporated areas. Control pCAGGS-GFP electroporated cells are dispersed randomly in the CP, whereas Foxg1introduced GFP ${ }^{+}$cells are clustered. C, D, pCAGGS-GFP alone or pCAGGS-GFP and pCAGGS-Foxg1 were introduced in a restricted number of Foxg $1^{-1-}$ cells. E-G, I-K, GFP, Ctip2, and Satb2

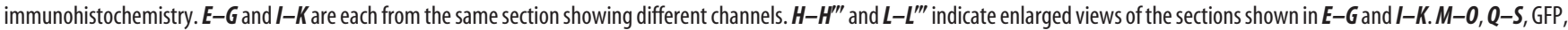
Ctip2, and Brn2 immunohistochemistry. $\boldsymbol{M} \mathbf{- O}$ and $\mathbf{Q}-\boldsymbol{S}$ are from the same section showing different channels. $\boldsymbol{P}-\boldsymbol{P}^{\prime \prime}$ ' and $\boldsymbol{T}-\boldsymbol{T}^{\prime \prime}$ indicate enlarged views of the sections shown in $\boldsymbol{M}-\mathbf{O}$ and $\mathbf{Q}-\boldsymbol{S}$. $\boldsymbol{U}-\boldsymbol{W}$, $\boldsymbol{Y}-\boldsymbol{A} \boldsymbol{A}$, Ctip2, Satb2, and Foxg 1 immunohistochemistry. $\boldsymbol{U}-\boldsymbol{W}$ and $\boldsymbol{Y}-\boldsymbol{A} \boldsymbol{A}$ are each from the same section showing different channels. $\boldsymbol{X}-\boldsymbol{X}^{\prime \prime}$ and $\boldsymbol{A B}-\boldsymbol{A} \boldsymbol{B}^{\prime \prime}$ indicate enlarged views of the sections shown in $\boldsymbol{U}-\boldsymbol{W}$ and $\boldsymbol{Y}-\boldsymbol{A A}$. Filled arrowheads indicate layer marker ${ }^{+}$cells that express GFP or Foxg1, and open arrowheads indicate layer marker ${ }^{+}$cells that are negative for GFP or Foxg1. Scale bars: $\boldsymbol{B}$,

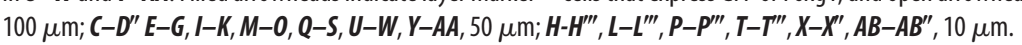


A

Foxg1\%; Rosa 26 1 loxp-stop-loxp-YFP/+
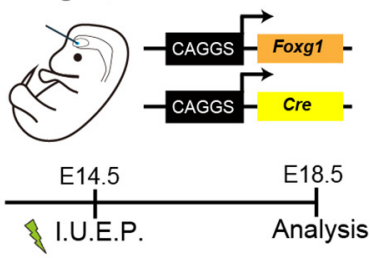
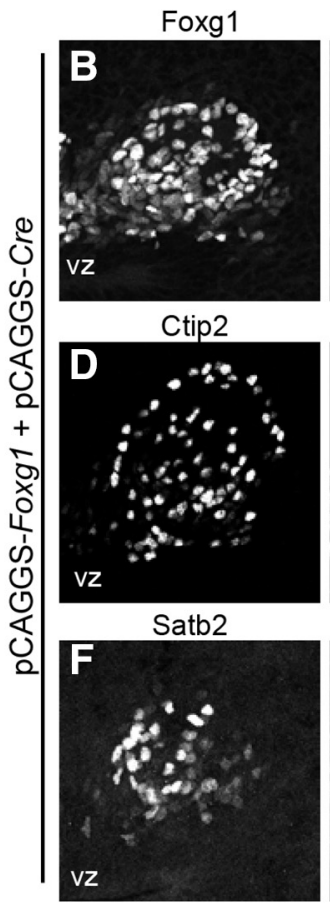

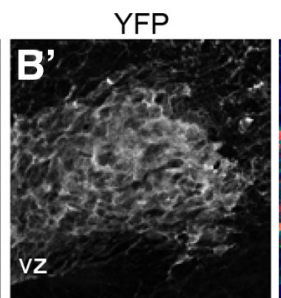

YFP

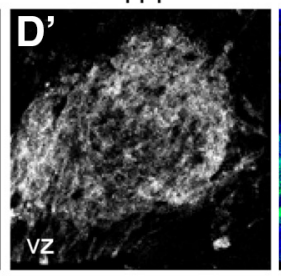

YFP

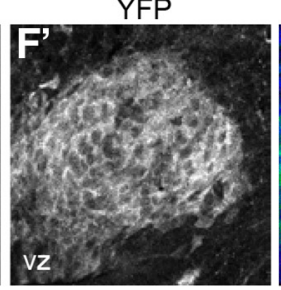

Foxg1YFPDAPI

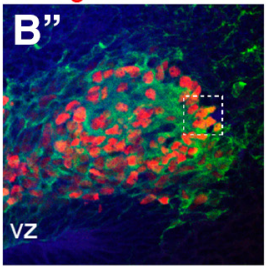

Ctip2YFPDAPI

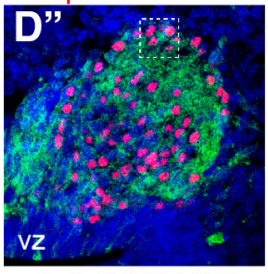

Satb2YFPDAPI

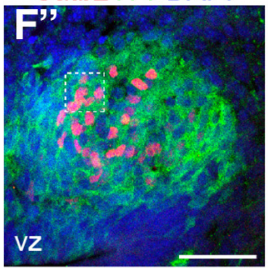

$\mathbf{E}$
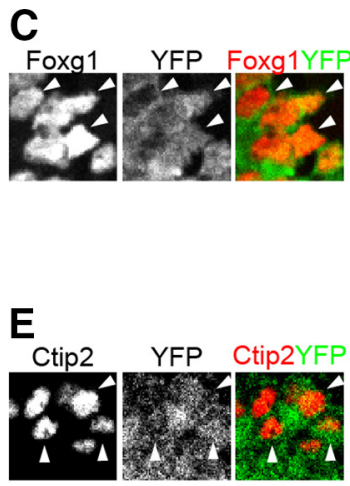

G

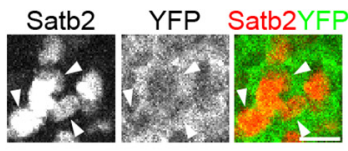

H
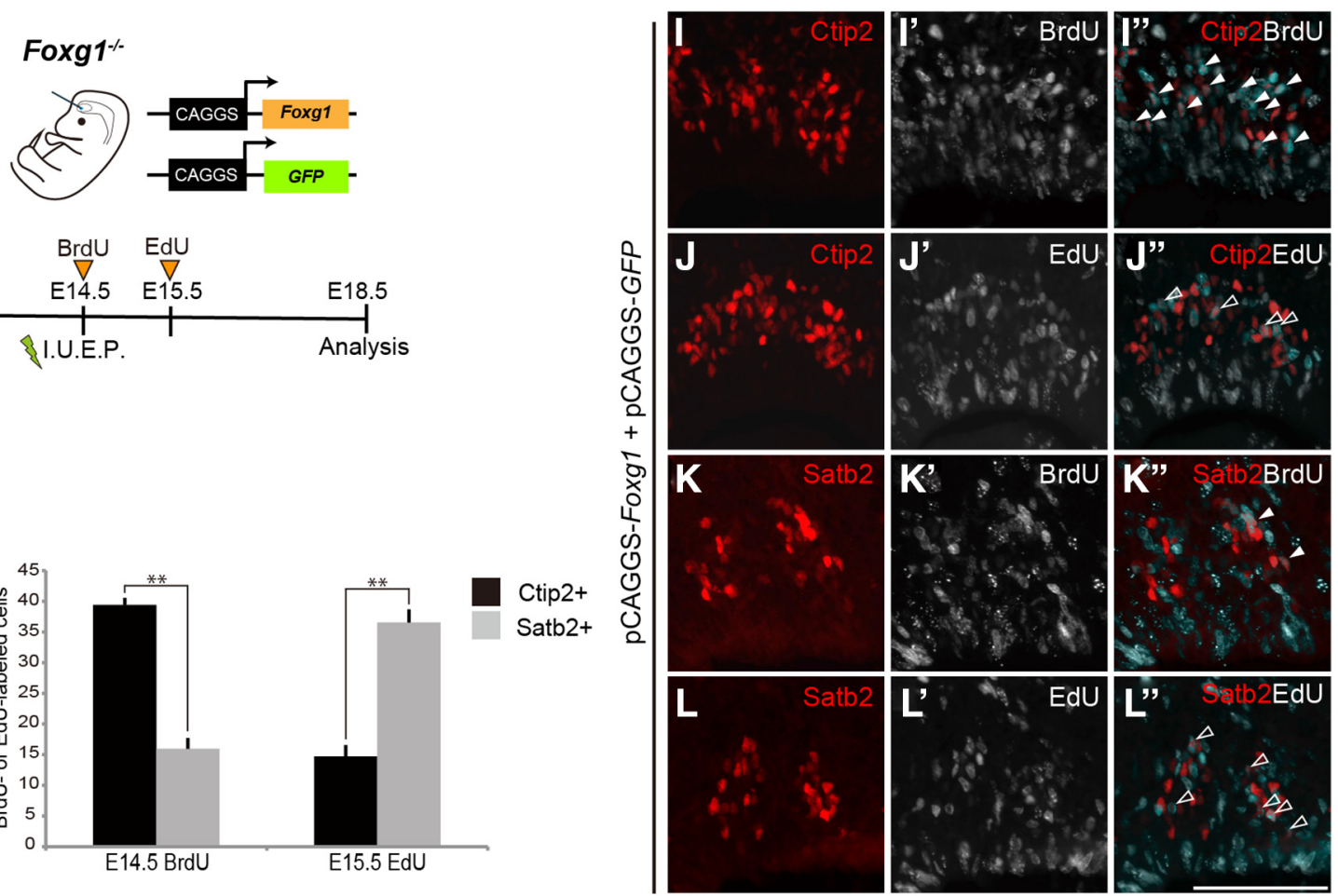

Figure 3. UL progenitors arise from the Foxg ${ }^{+}$cell lineage. $A$, Experimental design. I.U.E.P., In utero electroporation. B-G, Foxg1, YFP, Ctip2, and Satb2 immunohistochemistry images acquired by confocal microscopy. $\boldsymbol{C}, \boldsymbol{E}, \boldsymbol{G}$, Higher-magnification views of the boxed regions shown in $\boldsymbol{B}^{\prime \prime}, \boldsymbol{D}^{\prime \prime}$, and $\boldsymbol{F}^{\prime}$, respectively. Arrowheads indicate neurons that are double positive for the two indicated markers. In the Rosa $26^{\text {loxp-stop-loxp-YFP/+ }}$ reporter, YFP predominantly localizes to the cytoplasm. $\boldsymbol{H}$, Experimental design. $I-L^{\prime \prime}$, Double detection of BrdU or EdU with the following neuronal subtype markers: DL neurons, Ctip2; UL neurons, Satb2. Arrowheads indicate Ctip2 ${ }^{+}$or Satb2 ${ }^{+}$cells double labeled with BrdU, and open arrowheads indicate Ctip2 ${ }^{+}$or Satb2 ${ }^{+}$cells double labeled with EdU. $M$, Quantitative analysis of the percentage of $\mathrm{BrdU}^{+}$and EdU ${ }^{+}$cells that express Ctip2 or Satb2. The results are expressed as the mean \pm SEM. ${ }^{* *} p<0.01$. Scale bars: $\boldsymbol{B}-\boldsymbol{B}^{\prime \prime}, \boldsymbol{D}-\boldsymbol{D}^{\prime \prime}, \boldsymbol{F}-\boldsymbol{F}^{\prime \prime}, \boldsymbol{I}-\boldsymbol{L}^{\prime \prime}, 50 \mu \mathrm{m} ; \boldsymbol{C}, \boldsymbol{E}, \mathbf{G}$, $10 \mu \mathrm{m}$.

closed transcriptional network, in which cross-repression between the four TFs, namely, Fezf2, Ctip2, Satb2, and Tbr1, is sufficient to establish the subcerebral, intracortical, and corticothalamic projection identities within the postmitotic neurons
(Alcamo et al., 2008; Britanova et al., 2008; Chen et al., 2008; Han et al., 2011; McKenna et al., 2011; Srinivasan et al., 2012). We hypothesized that triggering a sequence of neurogenesis requires a break in this equilibrium, which occurs through a derepression 
of one of the genes in the transcriptional loop (Fig. 4A). Thus, we examined which of these TFs respond in vivo to Foxg1 induction. We assessed previous gene expression data in which E14.5, E15.0, E15.5, and E16.5 Foxg1 ${ }^{\text {tetOFoxg1 }}$ neocortical progenitors were isolated after Foxg1 induction by E14.5 Dox removal (Kumamoto et al., 2013; Fig. 4B). Using these datasets, one-way ANOVAs with post hoc tests were performed to identify differentially expressed transcripts (Fig. 4C; see Materials and Methods). According to these unbiased criteria, among the four TFs, only Tbr1 exhibited a significant response to Foxg1 induction [E16.5 Foxg1 induction/E14.5 control $=-0.9445\left(\log _{2}\right)$, corresponding to -1.9245 $\left(\log _{10}\right)$-fold change; Fig. $\left.4 C\right)$ ]. These results suggest that, within the aforementioned transcription network (Fig. 4A), Foxg1 may determine the sequence of layer neurogenesis primarily through Tbr1 repression. Notably, Tbr1 has been reported to be expressed in the majority of early-born glutamatergic neurons of the cerebral cortex, including preplate CR cells and subplate (SP) neurons (Hevner et al., 2001). Therefore, we assessed Tbr1 expression regulation during normal cortical development. Immunohistochemistry was performed using Tbr1 antibodies (Abcam rabbit anti-Tbr1 in Fig. $4 D-H$ and Millipore chicken anti-Tbr1, data not shown) and Foxg1 antibodies (Santa Cruz Biotechnology goat anti-Foxg1 in Fig. $4 D-H$ ). At E11.5, Tbr1 protein expression in preplate neurons preceded the onset of Foxg1 expression in the postmitotic neurons (Fig. 4D), which is consistent with the absence of Foxg1 expression in CR neurons (Hanashima et al., 2004). Instead, the Foxg1 protein was weakly detected in progenitor cells at this stage, in which the detection levels slightly varied between the different antibodies that were tested (Santa Cruz Biotechnology goat anti-Foxg1, Abcam rabbit anti-Foxg1, StemCulture rabbit anti-Foxg1, and rabbit antiFoxg1 from Y. Sasai; see Materials and Methods; Fig. 4D and data not shown). At E13.5, Foxg1 expression increased in progenitor cells and postmitotic neurons, in which its expression partially overlapped with Tbr1 ${ }^{+}$cells in the CP (Fig. 4E). The expression levels of the Foxg1 protein were higher in postmitotic neurons compared with progenitor cells in all stages that were examined; however, we observed downregulation of the Foxg1 protein during migration (Fig. $4 E, F$ ), which is consistent with a previous report (Miyoshi and Fishell, 2012). At E15.5, Tbr1 expression was downregulated in the cells of the upper part of the CP that were Foxg $1^{+}$, which consisted primarily of postmigratory layer $\mathrm{V}$ neurons (Fig. 4F). By postnatal day 4 (P4), Tbr1 and Foxg1 exhibited complementary expression patterns; Tbr1 was detected in L6 and SP within cells that were low or undetectable for the Foxg1 protein (Fig. 4G,H).

Next, we examined whether Foxg1 can regulate Tbr1 transcription by searching for Foxg1 consensus binding sites (Tao and Lai, 1992) within $10 \mathrm{~kb}$ of the transcription start site of the Tbr1 gene (Fig. 4I). We identified a $4 \mathrm{~kb}$ region of the mouse Tbr 1 promoter that consists of multiple conserved Foxg1 binding sequences (Fig. 4I), which were cloned upstream of the luciferase reporter gene to assess transcription. Cotransfection of pCAGGS-Foxg1 reduced the luciferase reporter activity in Neuro2a cells by $31.0 \pm 2.9 \%(p<0.01$; Fig. $4 J)$. These results indicated that Foxg1 can repress Tbr1 promoter activity in vitro.

We next assessed whether Foxg1 can repress Tbr1 expression in vivo. We used Foxg1 ${ }^{-1-}$ constitutive knock-out brains in which a loss of Foxg1 results in excessive production of the earliest-born CR cells in the cortex (Kumamoto et al., 2013). As expected in these cortices, we observed Tbr1 upregulation in the CP because of its expression in CR cells (Fig. 5B'; Hevner et al., 2001). Therefore, we coelectroporated pCAGGS-Foxg1 with
pCAGGS-GFP constructs into E14.5 Foxg1 ${ }^{-/-}$cortices and examined Tbr1 expression at E18.5 (Fig. 5A). Foxg1 induction cellautonomously repressed Tbr1 expression within this $\mathrm{GFP}^{+}$cell cluster (Fig. 5C-C", compared with control pCAGGS-GFP-only transfected cells in Fig. $5 B-B^{\prime \prime}$ ); Ctip2 (Fig. $5 C^{\prime \prime \prime}$ ) and Fezf2 (Fig. $\left.5 D^{\prime}\right)$ expression were only induced in this $\mathrm{Tbr}^{-} \mathrm{GFP}^{+}$population (Fig. $5 C^{\prime \prime \prime}, D-D^{\prime \prime \prime}$ ).

To further assess whether Foxg1 primarily represses Tbr 1 expression to derepress Fezf2/Ctip2 rather than indirectly induces Fezf2/Ctip2 expression through the repression of other TFs and thereby represses Tbrl as a downstream target gene within the transcription loop (Fig. 4A), we harvested pCAGGS-Foxg1 electroporated brains at an earlier time point ( $24 \mathrm{~h}$ after electroporation); we then examined Tbr1 and Ctip2 expression within the $\mathrm{GFP}^{+}$cells (Fig. $\left.5 A, E-L^{\prime \prime \prime}\right)$. Notably, $24 \mathrm{~h}$ was sufficient to repress Tbr1 in Foxg1 electroporated GFP ${ }^{+}$cells (Fig. $5 G-H, H^{\prime \prime}$ ). Furthermore, this downregulation of Tbrl preceded the onset of Ctip2 and Fezf2 protein induction (Fig. $\left.5 H^{\prime}, K-K^{\prime}, L-L^{\prime \prime \prime}\right)$. Moreover, in contrast to the control pCAGGS-GFP-only electroporated cortices, in which $\mathrm{GFP}^{+}$cells migrated into the Tbr $1^{+} \mathrm{CR}$ cell layer (Fig. $5 B-B^{\prime \prime}, E, F$ ), the Foxg1-introduced $\mathrm{GFP}^{+}$neurons failed to integrate into the overlaying supernumerary $\mathrm{CR}$ cell layer and accumulated beneath this layer (Fig. $5 C-C^{\prime \prime \prime}, G, H$ ). These distribution patterns again resembled the migration termination of projection neurons beneath the $\mathrm{CR}$ cell containing $\mathrm{MZ}$ during normal development.

Next, we assessed whether conditional removal of Foxgl expression during normal development resulted in Tbr1 upregulation in vivo. We generated Foxg1 conditional knock-out mice (cKO), in which Foxg1 was inactivated from E12.5 by Dox administration in the Foxg $1^{\text {tetOFoxg1 }}$ mice and examined cortices at E14.5 (E12.5 Foxg1 cKO harvested at E14.5; Fig. 6A,B). Notably, although Tbr1 expression was primarily restricted to postmigratory neurons within the $\mathrm{CP}$ in control cortices (Fig. $6 C-C^{\prime \prime \prime}$ ), the Tbrl protein was highly upregulated in early differentiating neurons that were Tuj1 ${ }^{+}$in the Foxg1 E12.5 cKO cortices (Fig. 6D$\left.D^{\prime \prime \prime}\right)$. This upregulation was accompanied by the loss of Fezf2 in the CP (Fig. $\left.6 F, F^{\prime}, F^{\prime \prime \prime \prime}\right)$. Furthermore, in the Foxg1 cKO cortices, we identified a loss of Ctip2 high-expressing cells in the upper part of the CP; however, low Ctip2 expression persisted throughout the CP, and Tbr1 and Ctip2 were coexpressed in these neurons (Fig. $\left.6 F^{\prime \prime}, F^{\prime \prime \prime}, F^{\prime \prime \prime \prime \prime}\right)$. These results further indicated that Tbr 1 upregulation in these mutants is attributed to the loss of Foxg1 expression rather than to the loss of Ctip2 expression within the transcriptional network (Fig. 4A), thus repressing Fezf2 independent of Ctip2 expression regulation (Fig. $4 A$ ). Consistent with this view, the segregation between Fezf ${ }^{+}$and Tbr ${ }^{+}$cells in the $\mathrm{CP}$ was detectable during normal development at E14.5 (control cortex; Fig. 6E, $E^{\prime}$ ) and primarily complementary at E15.5 (wildtype cortex; Fig. $\left.6 G, G^{\prime}, G^{\prime \prime}, G^{\prime \prime \prime \prime \prime}\right)$, at which point Ctip2 expression still broadly overlapped with Fezf $2^{+}$and Tbr $1^{+}$cells (Fig. $6 E-$ $\left.E^{\prime \prime \prime \prime \prime}, G-G^{\prime \prime \prime \prime \prime \prime}\right)$. Together, these data show that continued repression of Tbr 1 by Foxg1 is required for the acquisition of Fezf $2^{+} \mathrm{DL}$ neuron identity in the neocortex. Collectively, these results demonstrate that Tbr1 repression by Foxg1 confers the sequence of $\mathrm{DL}$ and UL competence by establishing the DL (Fezf2 ${ }^{\mathrm{ON}}$ / Satb2 ${ }^{\mathrm{OFF}} / \mathrm{Ctip} 2^{\mathrm{HI}}$ ) identity (Fig. $4 A$ ).

\section{Ablation of early postmitotic DL neurons prolongs DL competence at the expense of UL neurogenesis}

Tbr1 repression by Foxg1 favors the acquisition of a DL fate over an UL identity within the transcriptional network (Fig. 4A). Because of its nature, the subsequent transition from DL to UL 
A

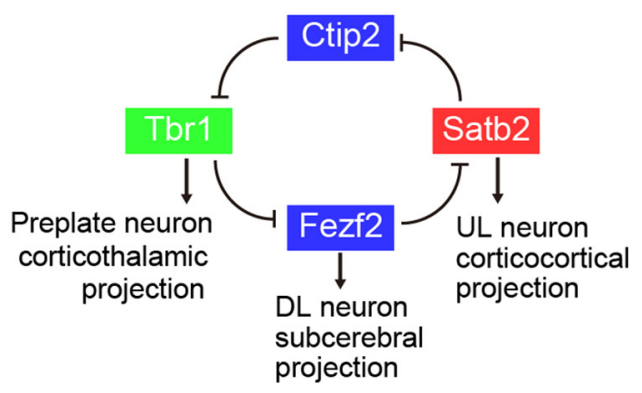

B

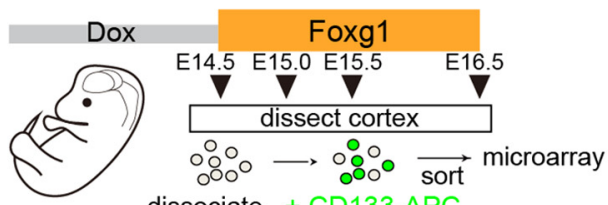

Foxg $1^{\text {tetofoxg } 1}$ cortex

dissociate + CD133-APC

(E14.5 Foxg1 induction)
Tbr1Foxg1

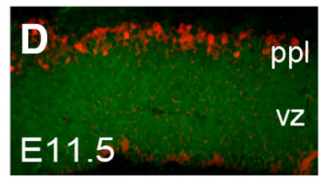

E

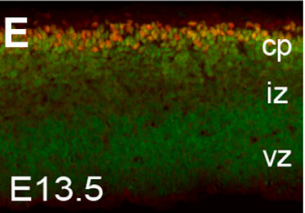

\section{$\mathbf{F}$}

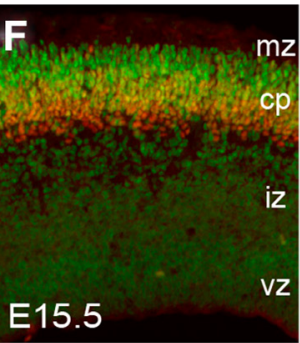

C

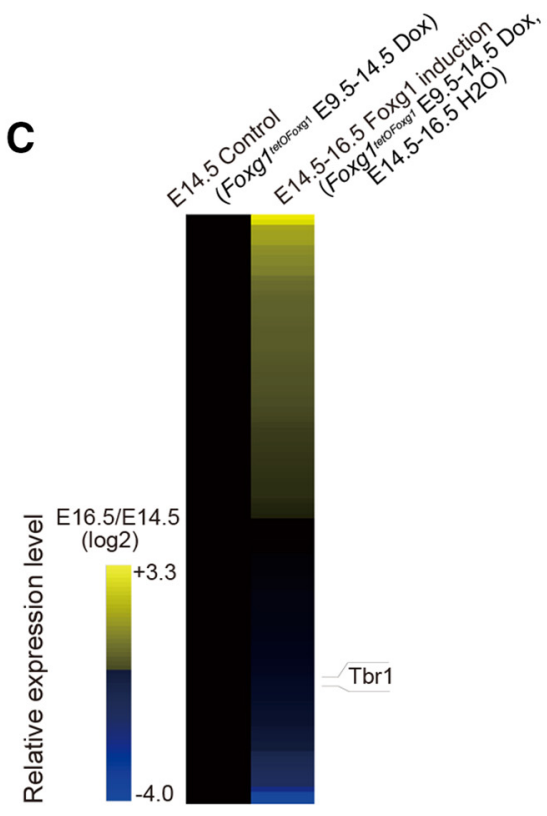

G

$\mathrm{mz}$

H

$12-4$

3.

L5

L6.

$\mathrm{sp}$

iz

E18.5 Vz

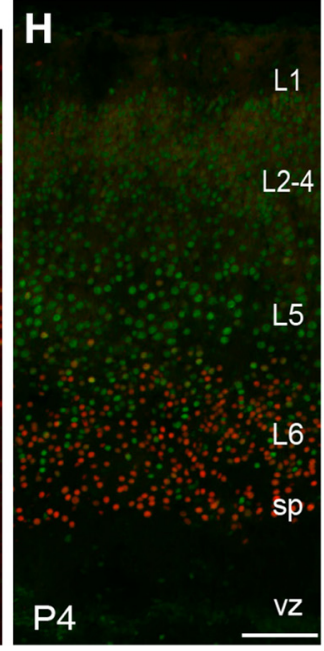

L1

L2-4

L5

L6

sp

vz

\section{I}

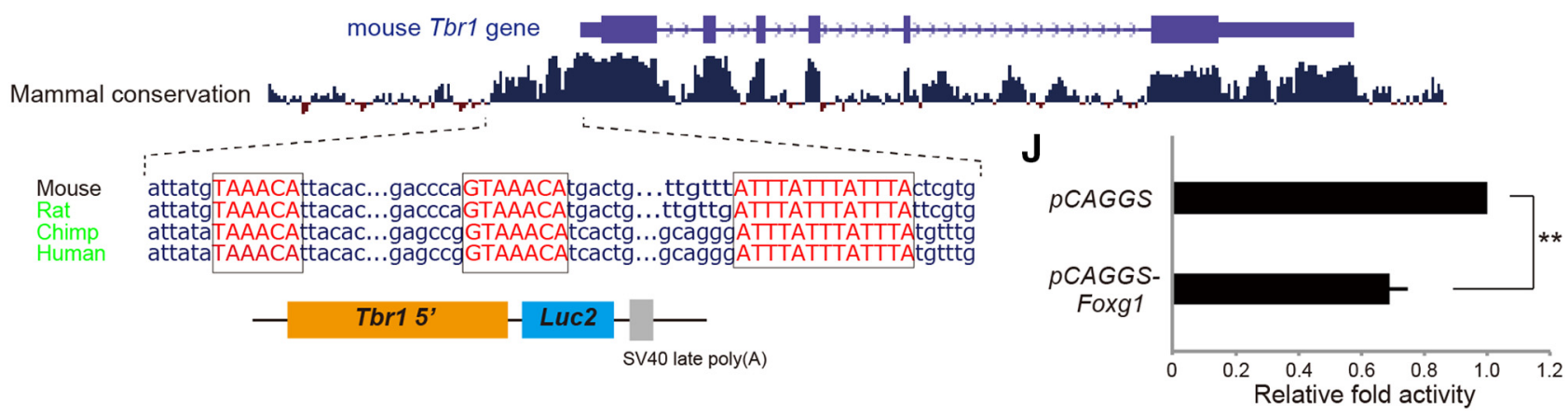

Figure 4. Foxg1 regulates Tbr1 transcription in vitro. $\boldsymbol{A}$, Schematic model of identified genetic interactions between the layer-subtype TFs. $\boldsymbol{B}$, Experimental scheme of the transcriptome analysis performed by Kumamoto et al., 2013. Temporal cohort of CD $133^{+}$cells isolated from Foxg $1^{\text {tetoFoxg1 }}$ mice, in which Foxg1 was induced from E14.5, was used as samples. C, Colored values represent relative fold changes in gene expression between the E16.5 Foxg ${ }^{\text {tetoFoxg1 }}$ cortex/E14.5 Foxg ${ }^{\text {tetofoxg } 1}$ cortex of all TFs that significantly responded to Foxg1 based on a five-dataset (E14.5, E15.0, E15.5, E16.5, and E15.5 Dox ${ }^{+}$negative control) ANOVA cluster analysis. Tbr1 probe: E16.5/E14.5-fold change $\left(\log _{2}\right)=-0.9445\left(\log _{10}=-1.9245\right)$. D-H, Developmental expression of Tbr1 (red) and Foxg1 (green) in E11.5, E13.5, E15.5, E18.5, and P4 wild-type cortices. Rabbit anti-Tbr1 (Abcam) and goat anti-Foxg1 (Santa Cruz Biotechnology) antibodies were used. Tissues from different stages were processed at identical conditions, with the exception that E18.5 $(\boldsymbol{G})$ and P4 $(\boldsymbol{H})$ brains were perfused before $1 \mathrm{~h}$ fixation. I, View of the mouse Tbr 1 gene locus (top), placental mammal basewise conservation by PhyloP (middle) and predicted Foxg1 binding sites of the Tbr1 promoter region (bottom). $J$, Luciferase reporter assay that used Tbr 1 promoter regions. Expression of pCAGGS-Foxg 1 repressed the luciferase activity of the Tbr 1 promoter constructs by $31.0 \pm 2.9 \%$. Error bars represent the SEM obtained from four replicates. Statistical analysis was performed using Student's $t$ test, ${ }^{* *} p<0.01$. Scale bars: $\boldsymbol{D}-\boldsymbol{H}, 50 \mu \mathrm{m}$. iz, Intermediate zone; ppl, preplate. 
A
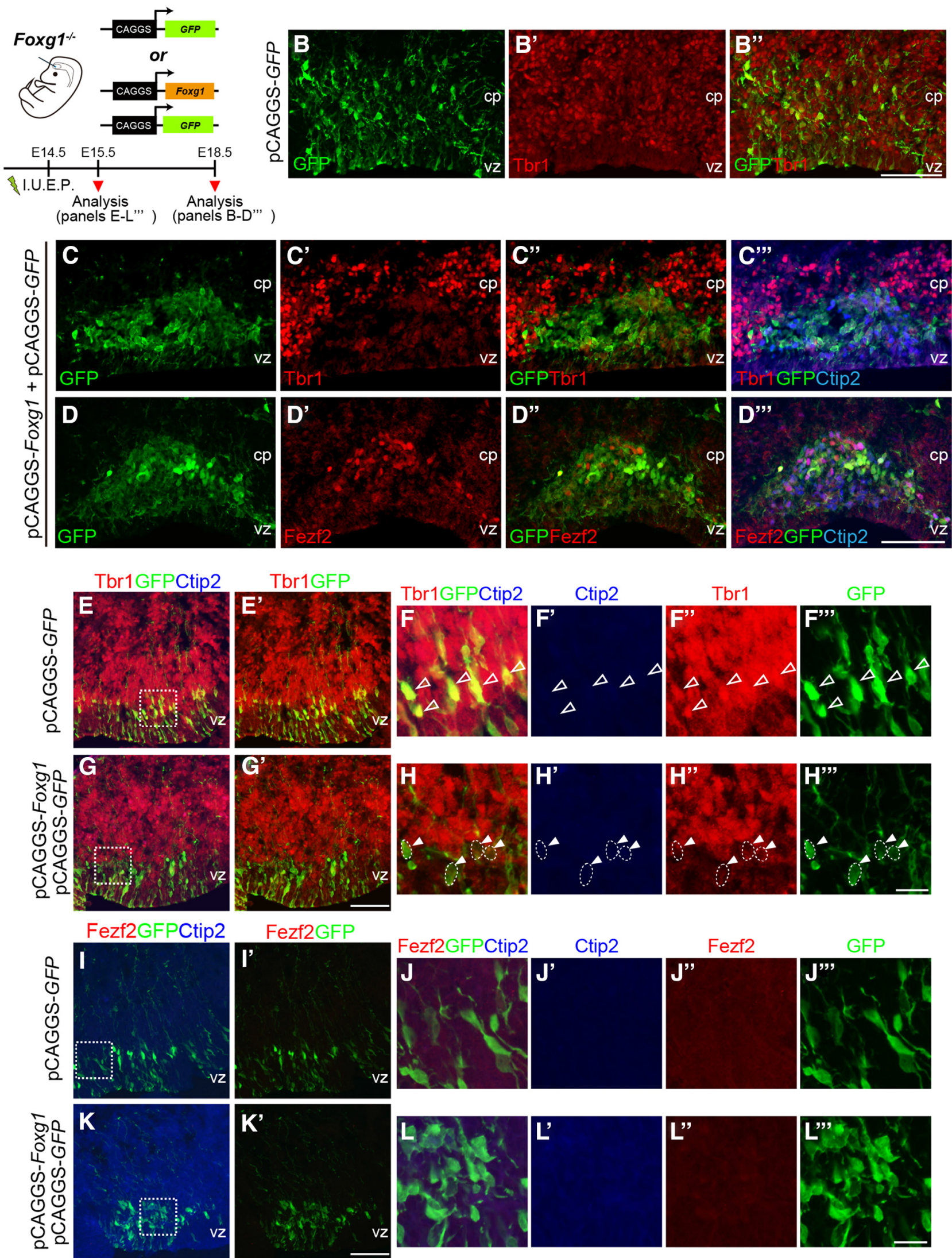

Figure 5. Foxg1 represses Tbr1 expression before Fezf2 and Ctip2 expression onset. $A$, Experimental scheme. Foxg $1^{-/-}$constitutive knock-out mice were used. I.U.E.P., In utero electroporation. $\boldsymbol{B}-\boldsymbol{D}^{\prime \prime \prime}$, GFP, Tbr1, Ctip2, and Fezf2 immunohistochemistry of E18.5 coronal sections from electroporated Foxg $1^{-1-}$ cortices. $\boldsymbol{B}-\boldsymbol{B}^{\prime \prime}, \boldsymbol{C}-\boldsymbol{C}^{\prime \prime}$, and $\boldsymbol{D}-\boldsymbol{D}^{\prime \prime}$ indicate a combination of different channels taken from the same sections. $\boldsymbol{E}-\boldsymbol{L}^{\prime \prime \prime}$, GFP, Tbr1, Ctip2, and Fezf2 immunohistochemistry of E15.5 coronal sections from electroporated Foxg $1^{-/-}$cortices. $\boldsymbol{F}-\boldsymbol{F}^{\prime \prime \prime}, \boldsymbol{H}-\boldsymbol{H}^{\prime \prime \prime}, \boldsymbol{J}-\boldsymbol{J}^{\prime \prime \prime}$, and $\boldsymbol{L}-\boldsymbol{L}^{\prime \prime \prime}$ indicate enlarged views of the boxed regions indicated in $E, G, I$, and $\boldsymbol{K}$, respectively. Filled arrowheads indicate GFP ${ }^{+}$cells that are $\mathrm{Tbr} 1^{-}$and Ctip2 $^{-}$. Open arrowheads indicate GFP ${ }^{+}$cells that are Tbr $1^{+}$ in controls. Scale bars: $\boldsymbol{B}-\boldsymbol{D}^{\prime \prime \prime}, \boldsymbol{E}-\boldsymbol{E}^{\prime}, \mathbf{G}-\boldsymbol{G}^{\prime}, \boldsymbol{I}-\boldsymbol{I}^{\prime}, \boldsymbol{K}-\boldsymbol{K}^{\prime}, 50 \mu \mathrm{m} ; \boldsymbol{F}-\boldsymbol{F}^{\prime \prime}, \boldsymbol{H}-\boldsymbol{H}^{\prime \prime \prime}, \boldsymbol{J}-\boldsymbol{J}^{\prime \prime \prime}, \boldsymbol{L}-\boldsymbol{L}^{\prime \prime \prime}, 10 \mu \mathrm{m}$. 

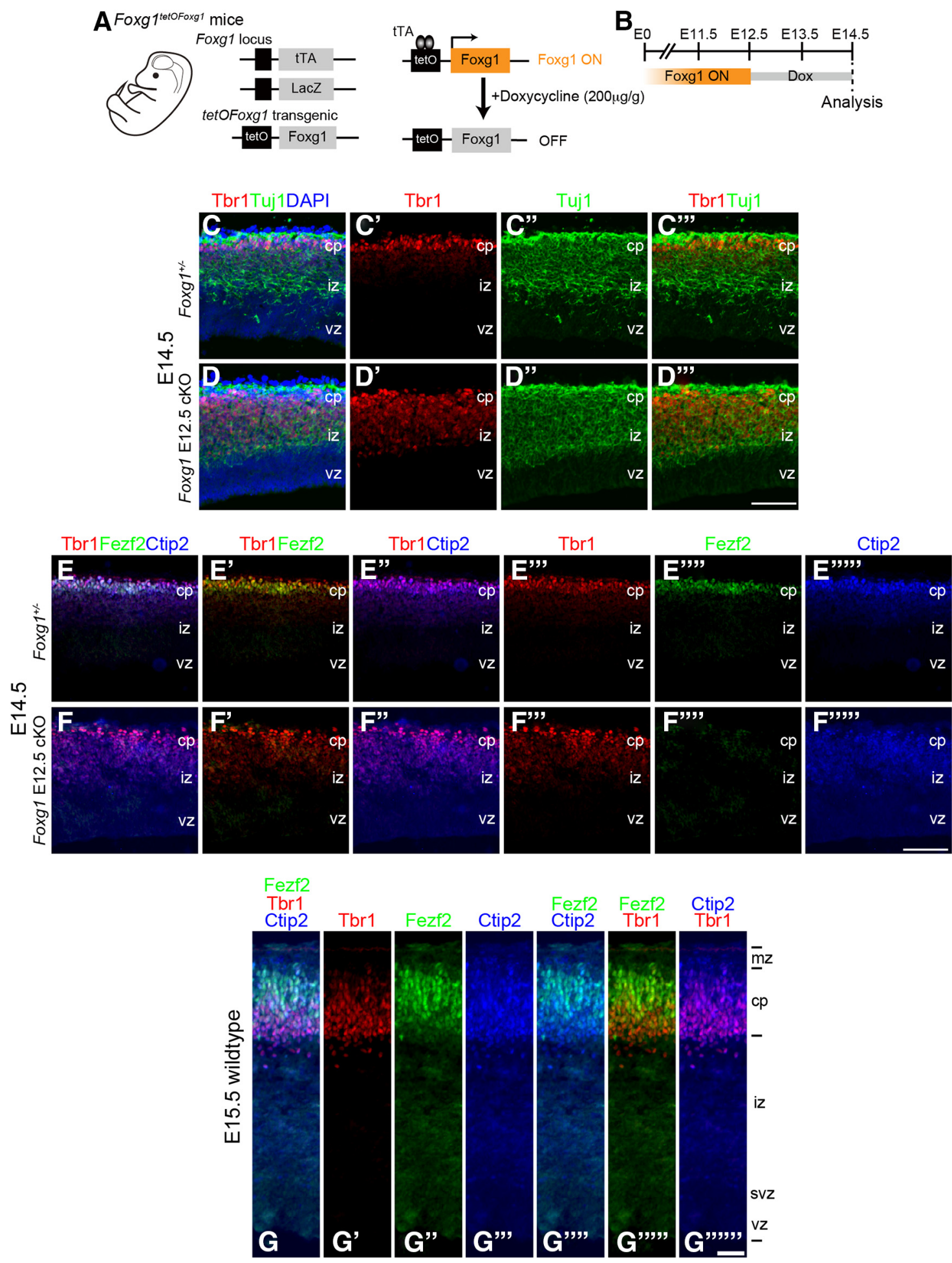

Figure 6. Conditional inactivation of Foxg1 at E12.5 results in Tbr1 upregulation and loss of Fezf2 expression. $A$, Experimental scheme. Foxg $1^{\text {tetOFoxg } 1}$ mice were used. Dox was administered at 200 $\mu \mathrm{g} / \mathrm{g}$ for constitutive suppression of Foxg1. B, Dox was administered from E12.5 (Foxg1 0FF) onward, and the embryos were harvested at E14.5. C-C', D-D'", Tbr1, Tuj1 immunohistochemistry,

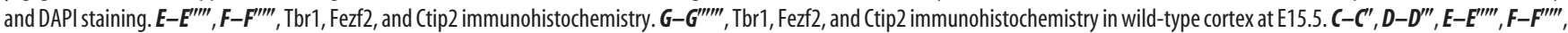
and $\mathbf{G}-\mathbf{G}^{\prime \prime \prime \prime \prime \prime \prime}$ indicate a combination of different channels taken from the same sections. Scale bars: $\mathbf{C}-\boldsymbol{C}^{\prime \prime}, \mathbf{D}-\mathbf{D}^{\prime \prime \prime}, \boldsymbol{E}-\boldsymbol{E}^{\prime \prime \prime \prime \prime}, \boldsymbol{F}-\boldsymbol{F}^{\prime \prime \prime \prime \prime}, 50 \mu \mathrm{m} ; \mathbf{G}-\boldsymbol{G}^{\prime \prime \prime \prime \prime \prime \prime}, 20 \mu \mathrm{m}$. iz, Intermediate zone.

competence requires the repression of DL determinants to terminate DL competence. Shortly after Foxg1 induction in the Foxg1 $1^{-/-}$cortices (24 h after electroporation; Fig. 7A), Foxg1introduced $\mathrm{GFP}^{+}$cells established apical and basal processes that contacted the ventricular surface and the CP (Fig. 7C, filled arrowheads and open arrowheads, respectively). Based on previous observations that UL neurons favor aggregate culture conditions (Shen et al., 2006; Eiraku et al., 2008; Gaspard et al., 2008; Kadoshima et al., 2013), we hypothesized that repressing the DL identity may require short-range negative feedback signals provided directly by the DL neurons. To directly assess whether postmitotic neurons propagate negative feedback signals that regulate 

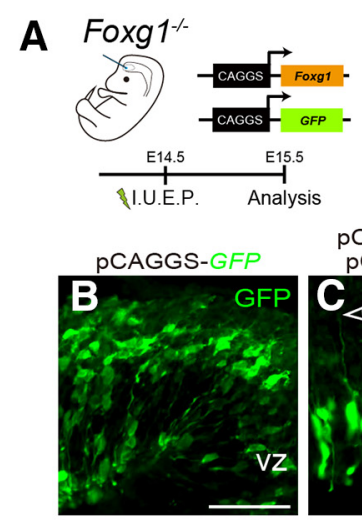

PCAGGS-Foxg1

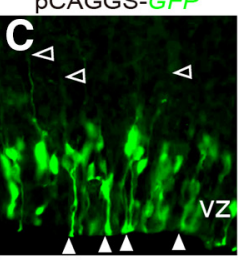

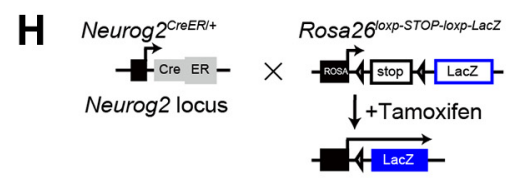

$$
\begin{array}{cccc} 
& \multicolumn{1}{c}{\begin{array}{c}
\text { Tam Analysis } \\
\frac{1}{t}
\end{array}} & \text { Analysis } \\
\hline \text { E11.5 } & 12.5 & 13.5 & 18.5
\end{array}
$$

K Nestin-CreER mice Rosa2610x-STOP-Loxp-Lacz

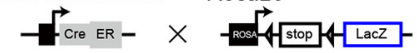
Nestin enhancer
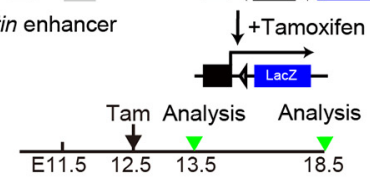

$\mathbf{N}$
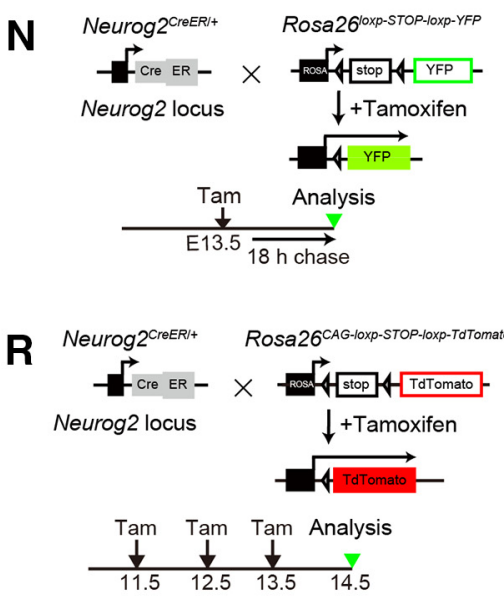
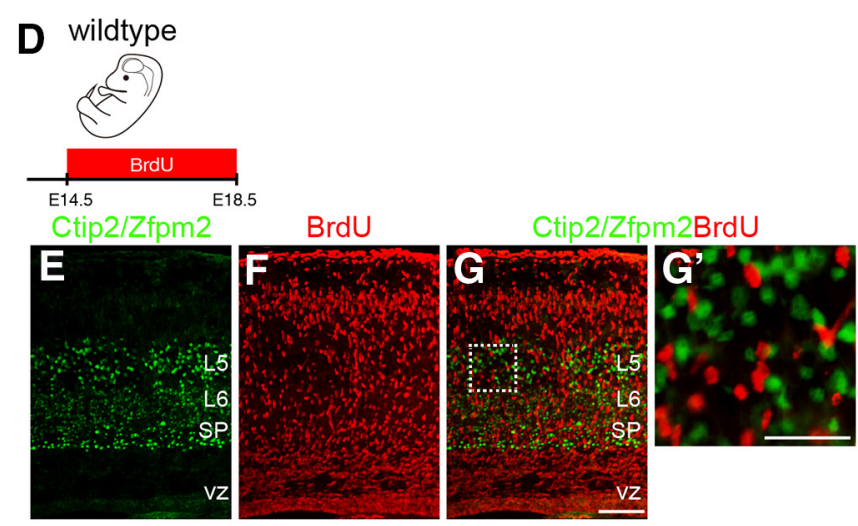

LacZ
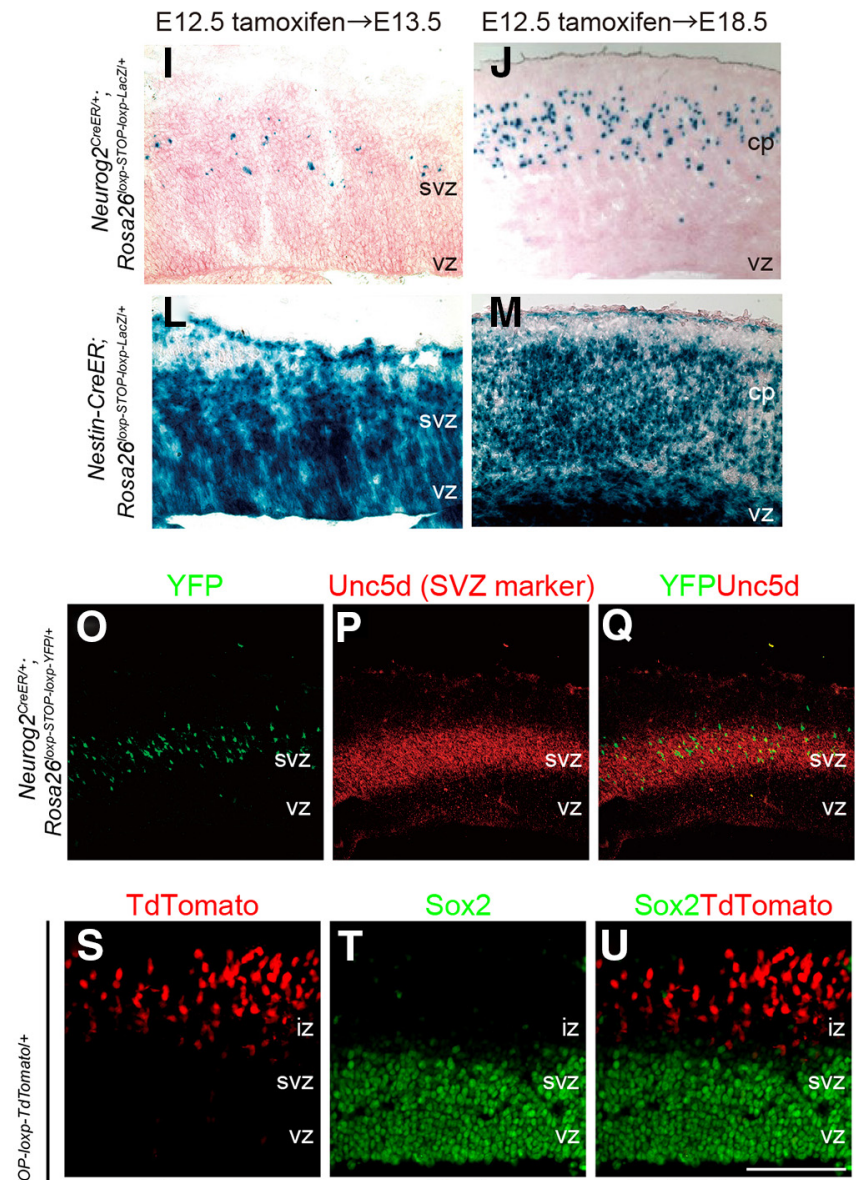

Sox2TdTomato

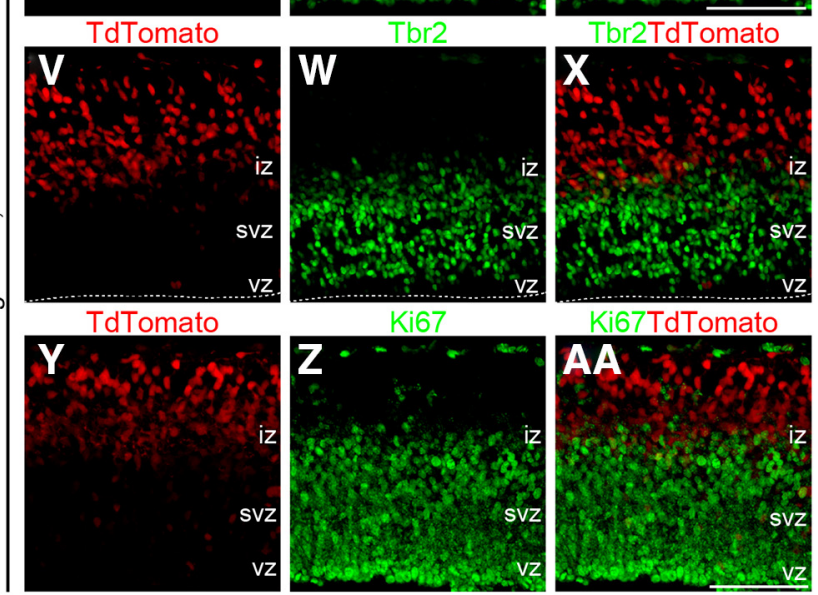


DL competence, we ablated postmitotic DL neurons using genetic approaches. To selectively manipulate DL neurons, we first assessed the termination of DL competence during normal development. E14.5 wild-type mice were labeled with a pulse of BrdU (50 mg/kg body weight) and were subsequently administered BrdU in their drinking water $(1.5 \mathrm{mg} / \mathrm{ml})$; then, DL neurogenesis was examined at E18.5 (Fig. 7D). We used Ctip2 and Zfpm2 (merged in green channel) immunohistochemistry to detect all DL neurons (layer V neurons, Ctip2 ${ }^{+}$; layer VI and SP neurons, Zfpm $2^{+}$; Kwan et al., 2008) and determined that almost no DL neurons were generated from E14.5 onward during normal development $\left(1.1 \pm 0.4 \% \mathrm{Ctip} 2^{+} \mathrm{Zfpm} 2^{+} / \mathrm{BrdU}^{+}\right.$cells; Fig. $\left.7 E-G^{\prime}\right)$.

To ablate postmitotic neurons, we used Neurog2 gene expression. A previous study reported dynamic Neurog2 protein expression during the cortical progenitor cell cycle; Neurog2 expression is low in the $\mathrm{Ki}^{+}{ }^{+}$cycling progenitors, but it is elevated in neuronally committed $\left(\mathrm{Ki}^{-} 7^{-}\right.$) cells (Miyata et al., 2001). We hypothesized that Neurog2 expression onset will allow the manipulation of early postmitotic neurons before the maturation of the DL identity necessary for negative feedback signal propagation. Therefore, we used the Neurog2 gene locus to drive the ablation of this population (Neurog $2^{\mathrm{CreER} /+}$ mice) (Zirlinger et al., 2002). First, we crossed the Neurog $2^{\mathrm{CreER} /+}$ mice with three distinct reporter lines to assess recombination within the cortical cells (Fig. $7 \mathrm{H}, \mathrm{N}, \mathrm{R}$ ). We crossed Neurog $2^{\mathrm{CreER} /+}$ mice with Rosa26 $6^{\text {loxp-stop-loxp-LacZ/+ }}$ reporter mice (Soriano 1999). When tamoxifen was administered at E12.5 and the cortices were examined at E13.5 (Fig. $7 H$ ), we identified a few labeled cells outside the VZ (Fig. 7I), and these labeled neurons occupied deeper laminar positions at E18.5 (Fig. 7J). This result was in contrast to the findings derived from a Nestin-CreER transgenic mouse line (Balordi and Fishell, 2007) crossed with the same Rosa26 $6^{\text {loxp-stop-loxp-lacZ/+ }}$ mice,

\footnotetext{
$\leftarrow$

Figure 7. Neurog $2^{\text {CreER/+ }}$ mice recombine early postmitotic neurons in the neocortex. $A$, Experimental scheme. Foxg $1^{-/-}$constitutive null mice were used. I.U.E.P., In utero electroporation. $\boldsymbol{B}, \boldsymbol{C}$, GFP immunohistochemistry of $50 \mu \mathrm{m}$ cortical slices. Foxg1-introduced GFP ${ }^{+}$cells established apical processes contacting the ventricular surface (filled arrowheads) and extended basal processes (open arrowheads). $\boldsymbol{D}$, Wild-type mice were used. Pregnant dams were administered a single-pulse BrdU injection at E14.5, and BrdU was subsequently administered in the drinking water. $\boldsymbol{E}-\mathbf{G}$, Ctip2 and Zfpm2 (merged in green) and BrdU immunohistochemistry in coronal sections $(12 \mu \mathrm{m})$ of E18.5 cortex. $\boldsymbol{G}^{\prime}$, Enlarged view of the boxed regions shown in $\boldsymbol{G}$. $\boldsymbol{H}, \boldsymbol{K}$, Schematic diagram of mouse lines crossed to assess Cre recombination. Tamoxifen was administered at the indicated dates to induce recombination, and neuronal labeling was analyzed at E13.5 and E18.5. I, J, $\beta$-gal histochemistry (blue) of Neurog $2^{\text {CreeR/ } /+} ;$ Rosa2 $6^{\text {loxp-stop-loxp-LacZ/+ }}$ mice. $L, M, \beta$-gal histochemistry (blue) of Nestin ${ }^{\text {CreER/+}} ;$ Rosa $26^{\text {loxp-stop-loxp-LacZ/+ }}$ mice. When tamoxifen was administered atE12.5 and examined at E13.5, a few labeled cells were observed outside the VZ (I). These labeled neurons had acquired deep laminar positions at E18.5 (J). This result was in contrast to that derived from a Nestin-CreER transgenic mouse line crossed with the same Rosa $26^{\text {loxp-stop-loxp-lacz/+ }}$ mice, in which recombination of the reporter allele occurred within the progenitors and labeled all progenitors and postmitotic neurons from E12.5 onward $(\boldsymbol{L}, \boldsymbol{M}) . \mathbf{N}$, Schematic diagram of the mouse lines. Neurog $2^{\text {CreER/+ }}$ mice were crossed with Rosa2 $6^{\text {loxp-stop-loxp-YFP/+ }}$ reporter mice. Tamoxifen was administered at E13.5 to induce recombination, and the embryos were analyzed $18 \mathrm{~h}$ after tamoxifen administration. $\mathbf{0}-\mathbf{Q}$, Double immunohistochemistry of GFP and Unc5d, an SVZ marker. These data confirmed labeled cells within the SVZ but not within the VZ. $\boldsymbol{R}$, Schematic diagram of the mouse lines that were crossed to label early postmitotic neurons using a distinct reporter

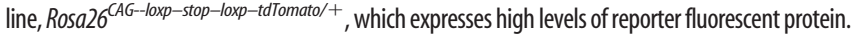
Tamoxifen was administered on the indicated dates to induce recombination, and the embryos were analyzed at E14.5. S-AA, Double immunohistochemistry of Sox2 (radial glial progenitor marker; $\boldsymbol{S}-\boldsymbol{U}$ ), Tbr2 (basal progenitor marker; $\boldsymbol{V}-\boldsymbol{X}$ ), and Ki67 (proliferative cell marker; $\boldsymbol{Y}-\boldsymbol{A A}$ ) with RFP. These data suggested that the Neurog $2^{\text {(reeR/+ }}$ line is capable of labeling postmitotic neurons, but not progenitor cell populations, during serial tamoxifen administration at E11.5E13.5. Scale bars: $\boldsymbol{B}-\boldsymbol{C}, \boldsymbol{E}-\boldsymbol{G}, \mathbf{S}-\boldsymbol{A} \boldsymbol{A}, 50 \mu \mathrm{m} ; \boldsymbol{G}^{\prime}, 20 \mu \mathrm{m}$. iz, Intermediate zone.
}

in which recombination of the reporter allele occurred within the progenitors and labeled all progenitors and postmitotic neurons from E12.5 onward (Fig. $7 K-M$ ). We further crossed Neurog $2^{\text {CreER/+ }}$ mice with Rosa26 $6^{\text {loxp-stop-loxp-YFP/+ }}$ reporter mice (Srinivas et al., 2001) and administered tamoxifen at E13.5 to induce recombination; the embryos were analyzed $18 \mathrm{~h}$ later (Fig. $7 N-Q)$. Double immunohistochemistry of GFP and Unc5d, which is a subventricular zone (SVZ) marker, confirmed labeled cells within the SVZ but not the VZ. We further used a Rosa26 $6^{\text {CAG-loxp-stop-loxp-tdTomato/+ }}$ reporter mouse line that expresses high levels of reporter fluorescent protein during recombination (Madisen et al., 2010). Tamoxifen was administered on 3 consecutive days (noon of E11.5, E12.5 and E13.5) to induce recombination, and the embryos were analyzed at E14.5 (Fig. $7 R$ ). Double immunohistochemistry of Sox2 (a radial glial progenitor marker), Tbr2 (a basal progenitor marker), and Ki67 (a proliferating cell marker that is expressed in all mitotic cells) with RFP confirmed Neurog $2^{\mathrm{CreER} /+}$ recombination in postmitotic neurons during tamoxifen administration at E11.5-E13.5 but not the Sox $2^{+}$(Fig. $7 S-U$ ), Tbr ${ }^{+}$(Fig. $7 V-X$ ), or Ki67 ${ }^{+}$(Fig. $7 Y-$ $A A)$ progenitor cell populations (Fig. $7 S-A A$ ).

To ablate early postmitotic DL neurons, we used diphtheria toxin A chain (DTA) expression driven from the same Rosa26 locus (Rosa26 loxp-stop-loxp-dta/+ line; Ivanova et al., 2005). Neurog $2^{\mathrm{CreER} /+}$ mice crossed with Rosa26 $6^{\text {loxp-stop-loxp-dta/+ }}$ mice were administered tamoxifen at E11.5, E12.5, and E13.5 to induce cell death in the DL cells (Fig. 8A). Consistent with the ablation of DL neurons, we confirmed a significant decrease in Ctip2/ $\mathrm{Zfpm}^{+}{ }^{+}$neurons at E14.5 (merged in red, $150.0 \pm 23.2$ cells in DL-ablated cortices and $408.0 \pm 14.3$ cells in controls, $p<0.01$; Fig. $\left.8 B-C^{\prime}, F\right)$. In contrast, Tbr ${ }^{+}$cell number was maintained $(276.3 \pm 27.6$ cells in DL-ablated cortices and $258.3 \pm 6.9$ cells in controls, $p=0.63$, not significant; Fig. $8 D-E^{\prime}, G$ ), indicating that progenitor cells were not eliminated by this ablation, consistent with the absence of Neurog $2^{\mathrm{CreER} /+}$-mediated recombination in this population (Fig. $7 S-A A$ ). Therefore, we assessed the effects of DL ablation on neocortical neurogenesis by quantifying the number of DL and UL neurons at E18.5 (Fig. $8 H$ ). We determined that the number of Ctip $2^{+}$neurons also decreased at this stage ( $501 \pm 45$ cells in DL-ablated cortices vs $713 \pm 8.6$ cells in controls, $p<0.01$; Fig. $8 I, J, O)$. Notably, at E18.5, the production of Satb $2^{+}$neurons in these animals also slightly decreased $(677 \pm$ 85 cells in DL-ablated cortices vs $1079 \pm 61$ cells in controls, $p<$ 0.05 ; Fig. $8 K, L, O)$, and the proportion of Ctip ${ }^{+}$and Satb $2^{+}$ cells was comparable with the controls (Ctip2 ${ }^{+}$cells/all marker ${ }^{+}$ cells; $40.8 \pm 1.8 \%$ in DL-ablated cortices vs $39.4 \pm 1.4 \%$ in controls, $p=0.63$, not significant, Satb ${ }^{+}$cells/all marker ${ }^{+}$cells; $54.2 \pm 1.6 \%$ in DL-ablated cortices vs $59.2 \pm 1.6 \%$ in controls, $p=0.1$, not significant; Fig. $\left.8 M-N^{\prime}, P\right)$. To confirm these results, we used an alternative marker for UL neurons, Cux1, which is expressed in most UL neurons (Nieto et al., 2004). The ablation of DL neurons also reduced the number of Cux1 ${ }^{+}$cells at E18.5 (1206 \pm 74 cells in DL-ablated cortices vs $1393 \pm 75$ cells in controls, $p<0.01$; Fig. $8 S, T, W)$. This ablation resulted in a similar ratio of Ctip ${ }^{+} / \mathrm{Cux} 1^{+}$neurons compared with controls at E18.5, in which the proportions of Ctip $2^{+}$or Cux $1^{+}$cells were not significantly different $\left(\mathrm{Ctip} 2{ }^{+}\right.$cells/all marker ${ }^{+}$cells; $36.2 \pm$ $0.8 \%$ in DL-ablated cortices vs $37.0 \pm 1.1 \%$ in controls, $p=0.58$, not significant, $\mathrm{Cux}^{+}{ }^{+}$cells/all marker ${ }^{+}$cells; $63.6 \pm 0.8 \%$ in DL-ablated cortices vs $62.7 \pm 1.0 \%$ in controls, $p=0.48$, not significant; Fig. $\left.8 U-V^{\prime}, X\right)$.

Because the relative DL neuron/UL neuron ratio was maintained despite the ablation of a significant number of DL neurons 
$\mathbf{A}$
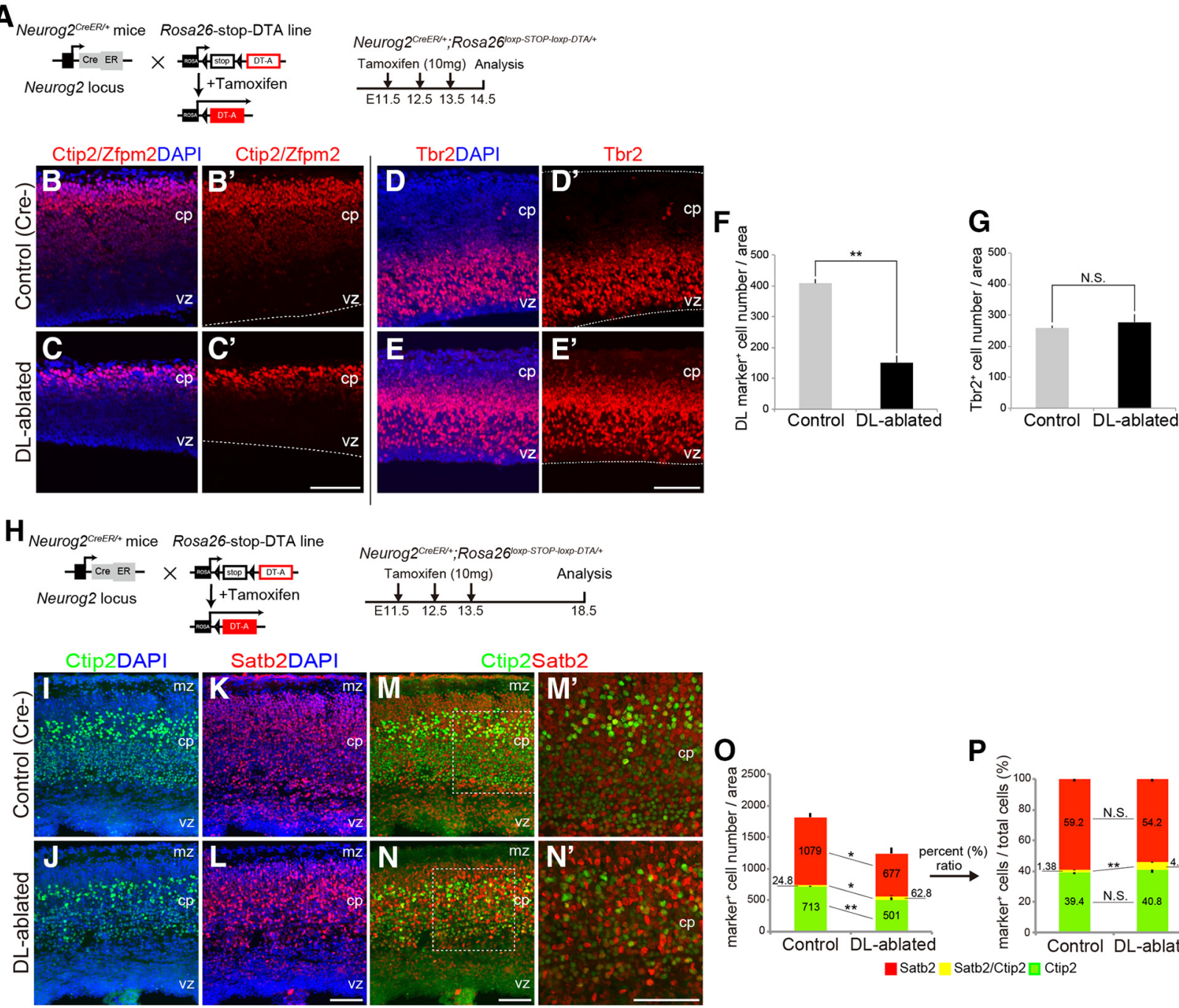

Satb2DAPI
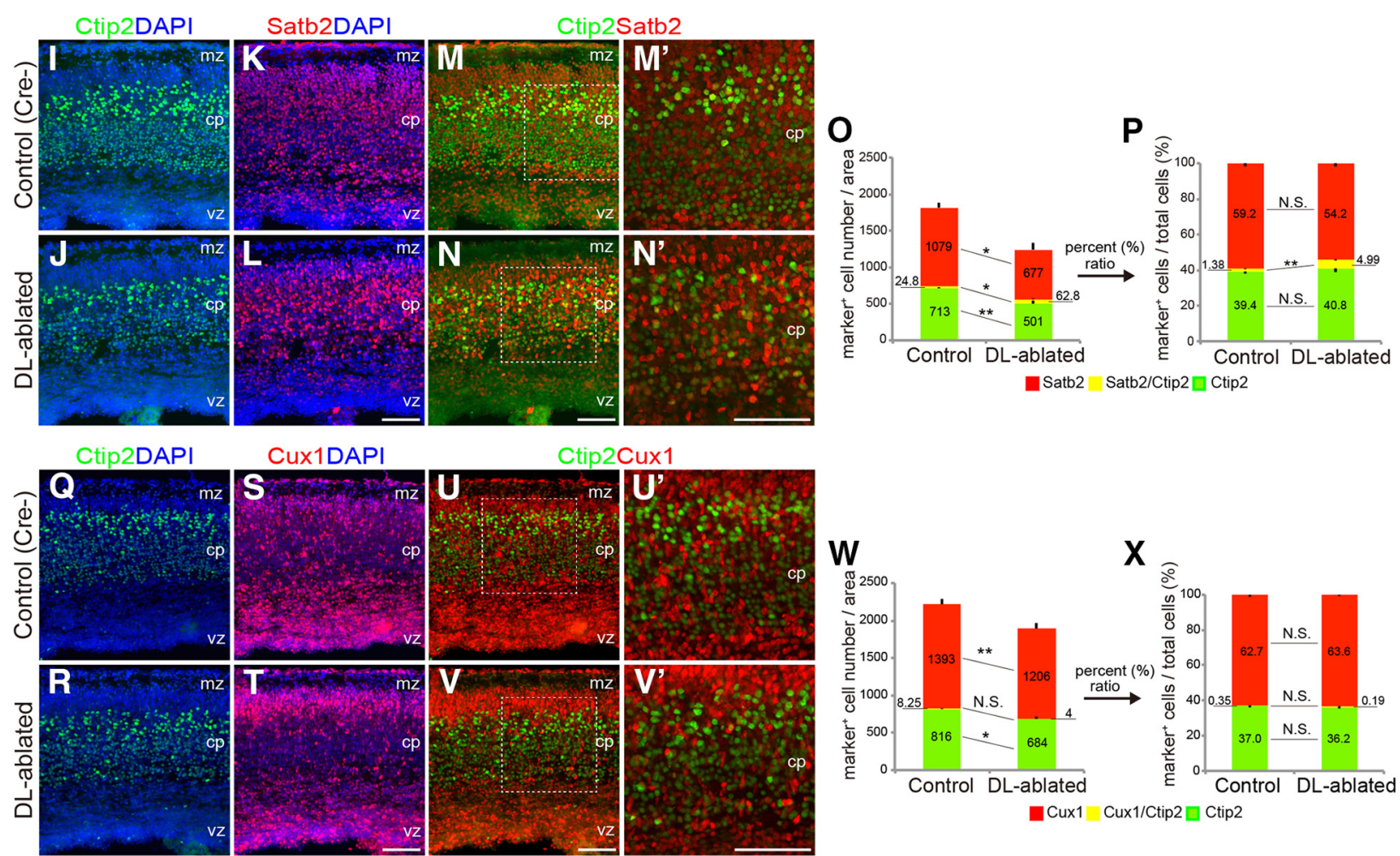

Figure 8. Neuronal subtype ratio is maintained despite genetic DL neuron ablation. $A$, Schematic diagram of the mouse lines that were crossed to ablate $D L$ neurons. Tamoxifen was administered on the indicated dates to induce neuronal ablation. The embryos were analyzed at E14.5. $\boldsymbol{B}-\boldsymbol{E}^{\prime}$, Immunohistochemistry of Pan-DL markers (Ctip2 and Zfpm2, merged in red; $\left.\boldsymbol{B}-\boldsymbol{C}^{\prime}\right)$ and Tbr2 (D- $\left.\boldsymbol{E}^{\prime}\right)$ in Neurog $2^{\text {CreeR/+ }} ;$ Rosa2 $6^{\text {loxp-stop-loxp-dta/+ }}$ mice (DL-ablated) and tamoxifen-administered wild-type littermate controls. F, G, Quantitative analysis. The total number of cells that expressed Ctip2 and Zfpm2 $(\boldsymbol{F})$ or Tbr2 (G) per $100 \mu \mathrm{m}$ cortical strip from the dorsolateral cortex was counted. The data represent the mean \pm SEM values. ${ }^{* *} p<0.01$. N.S., Not significant. $\boldsymbol{H}$, Schematic diagram of the mouse lines that were crossed to ablate DL neurons. Tamoxifen was administered on the indicated dates to induce neuronal ablation. The embryos were analyzed at E18.5. I-N, Ctip2 and Satb2 immunohistochemistry in Neurog $2^{\text {(reER/+ }} ;$ Rosa2 $6^{\text {loxp-stop-loxp-dta/+ }}$ mice (DL-ablated) and Rosa26 $6^{\text {loxp-stop-loxp-dta/+ }}$ mice (controls). $\boldsymbol{M}^{\prime}, \boldsymbol{N}^{\prime}$, Enlarged view of the boxed regions shown in $\boldsymbol{M}$ and N. O, Quantitative analysis of absolute marker ${ }^{+}$cell number per unit area: Satb2 ${ }^{+}$only (red), Ctip2 ${ }^{+}$only (green), and Ctip2 ${ }^{+}$and Satb2 ${ }^{+}$(yellow) cells. The total number of cells per $260-\mu \mathrm{m}$-wide cortical strips from the dorsolateral cortices was counted. $\boldsymbol{P}$, Quantitative analysis of the proportion of marker ${ }^{+}$cells in same radial strips used in $\mathbf{0}:$ Satb2 $^{+}$only (red), (Ctip2 ${ }^{+}$only (green), and Ctip2 ${ }^{+}$and Satb2 ${ }^{+}$(yellow) cells of the total cells that expressed either of the two (Ctip2 or Satb2) markers. Q-V, Ctip2 and Cux1 immunohistochemistry in Neurog $2^{\text {CreeR/+ }} ;$; Rosa2 $2^{\text {loxp-stop-loxp-dta/+ }}$ mice (DL-ablated) and Rosa26 $6^{\text {loxp-stop-loxp-dta/+ }}$ mice (controls). $\boldsymbol{U}^{\prime}, \boldsymbol{V}^{\prime}$, Enlarged view of the boxed regions shown in $\boldsymbol{U}$ and $\boldsymbol{V}$. $\boldsymbol{W}$, Quantitative analysis of absolute marker ${ }^{+}$cell number per unit area: $\mathrm{Cux}^{+}{ }^{+}$only (red), Ctip2 ${ }^{+}$only (green), and Ctip2 ${ }^{+}$and Cux ${ }^{+}$(yellow) cells. The total number of cells per 260- $\mu \mathrm{m}$-wide cortical strips from the dorsolateral cortices was counted. $\boldsymbol{X}$, Quantitative analysis of the proportion of marker ${ }^{+}$cells in same radial strips used in $\boldsymbol{W}$ : Cux ${ }^{+}$only (red), Ctip2 ${ }^{+}$only (green), and Ctip2 ${ }^{+}$and Cux ${ }^{+}$(yellow) cells of the total cells that expressed either of the two (Ctip2 or Cux1) markers. The data represent the mean \pm SEM values. ${ }^{*} p<0.05,{ }^{* *} p<0.01$. Scale bars: $\boldsymbol{B}-\boldsymbol{E}^{\prime}, \mathbf{I}-\boldsymbol{N}^{\prime}, \boldsymbol{Q}-\boldsymbol{V}^{\prime}, 50 \mu \mathrm{m}$. N.S., Not significant. 

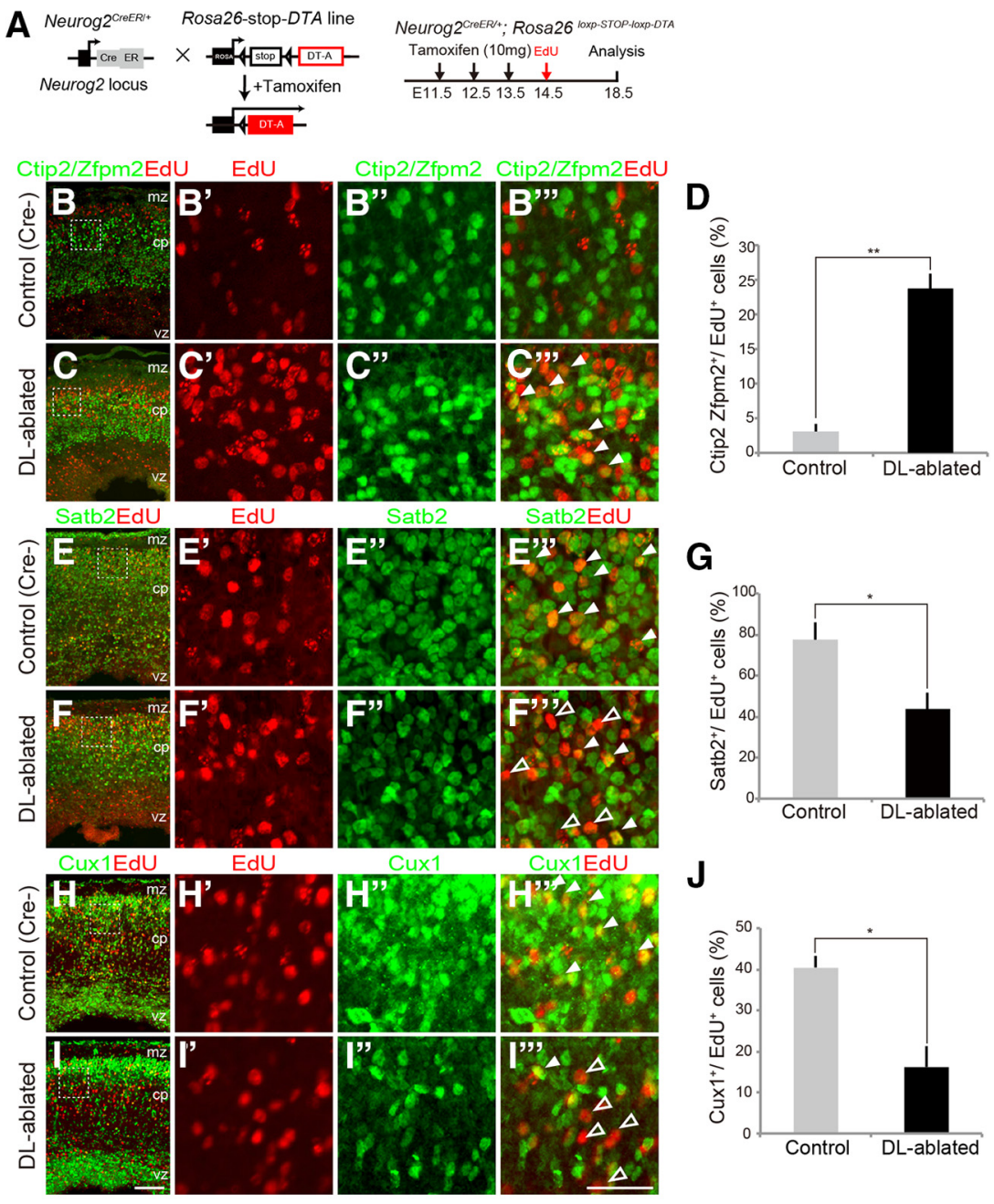

$\mathbf{K}$

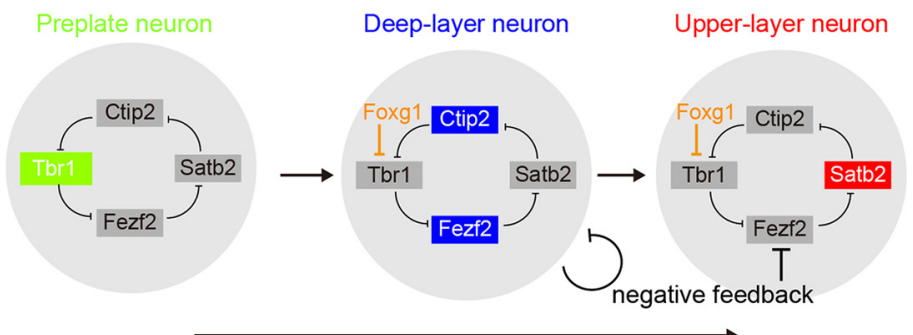

development (time)

Figure 9. Ablation of postmitotic $D L$ neurons prolongs $D L$ competence at the expense of $U L$ neurogenesis. $A$, Experimental scheme. $\boldsymbol{B}-\boldsymbol{I}$, Immunohistochemistry of EdU and pan-DL markers (Ctip2 and Zfpm2, merged in green) or UL markers (Satb2 and Cux1). $\boldsymbol{B}^{\prime \prime \prime}-\boldsymbol{I}^{\prime \prime \prime}$, Filled arrowheads indicate Ctip2 ${ }^{+} / \mathrm{Zfpm2}{ }^{+}$, Satb2 ${ }^{+}$, or Cux ${ }^{+}$cells double labeled with EdU, and open arrowheads indicate Satb2 ${ }^{-}$or Cux1 ${ }^{-}$EdU ${ }^{+}$cells. D, G, J, Quantitative analysis of the percentage of EdU ${ }^{+}$cells that expressed pan-DL markers (Ctip2 and Zfpm2) or UL markers (Satb2 and (ux1). The results are expressed as the mean \pm SEM. ${ }^{*} p<0.05$, ${ }^{* *} p<0.01$. Scale bars, $50 \mu \mathrm{m} . \boldsymbol{K}$, A model for the switch in layer-specific subtypes. Before Foxg1 expression, preplate cells express Tbr1 by default, most likely through one or more transcription activator(s) binding to the Tbr1 promoter region. The mechanism of Satb2 repression in preplate cells is unclear; Satb2 expression may require appropriate transcription activator(s) downstream of Foxg1. After its induction, Foxg1 initiates general projection neuron competence through global gene suppression (Kumamoto et al., 2013) and also suppresses Tbr1, which causes progenitor cells to acquire the DL $\left(\right.$ Fezf $2^{\mathrm{ON}} / \mathrm{Satb2}^{\mathrm{OFF}} / \mathrm{Ctip}^{\mathrm{ON}}{ }^{\mathrm{N}}$ ) identity. Finally, the transition from DL to UL neurogenesis requires a feedbacksignal from postmitotic DL cells that represses Fezf2/Ctip2 and, thus, confers the UL (Fezf2 ${ }^{\mathrm{OFF}} / \mathrm{Satb2}{ }^{\mathrm{ON}} / \mathrm{Ctip}^{2}{ }^{\mathrm{OFF}}$ ) identity.

(Fig. $8 B-C^{\prime}, F$ ), this finding prompted us to investigate whether the elimination of DL neurons affects the temporal window for DL competence. We injected EdU at E14.5 to monitor the neurons that were born from progenitors in post-ablated cortices (Fig. 9A) using pan-DL neuronal markers. Consistent with the previous results (Fig. $7 D-G^{\prime}$ ), we found almost no Ctip2/Zfpm2 ${ }^{+}$cells that were colabeled with EdU in the control $\left(\right.$ Rosa2 $\left.6^{\text {loxp-stop-loxp-dta/+}}\right)$ cortices $(3.1 \pm$ $1.1 \%$; Fig. $\left.9 B-B^{\prime \prime \prime}, D\right)$. Remarkably, in Neurog $2^{\text {CreER/+ }} ;$ Rosa $26^{\text {loxp-stop-loxp-dta/+ }}$ (DL-ablated) cortices, $23.7 \pm 2.2 \%(p<$ $0.01)$ of $\mathrm{EdU}^{+}$cells were colabeled with Ctip2 or Zfpm2 (Fig. $9 C-C^{\prime \prime \prime}, D$ ), which indicates that the ablation of DL neurons prolonged the production period of DL neurons. These results also suggest that the observed total number of DL neurons at E18.5 (Fig. 8O) included neurons that were generated after ablation, and therefore, the number of ablated neurons appears under-represented in this population. Next, we assessed whether feedback signaling propagated from DL neurons is required only to terminate the DL competence or this signaling also drives UL competence. In the latter case, the number of UL neurons born at E14.5 was expected to decrease in the DL-ablated cortices compared with the controls. Consistent with the general decrease in the Satb $2^{+}$neuron population (Fig. 8O), we determined that Satb2 ${ }^{+}$cells born at E14.5 $\left(\mathrm{EdU}^{+}\right.$cells $)$also decreased at the expense of increased DL production (77.5 $\pm 8.2 \%$ in control cortices and $43.5 \pm 7.8 \%$ in DL-ablated cortices, Satb $2{ }^{+} / \mathrm{EdU}^{+}$cells, $p<0.05$; Fig. $9 F-$ $\left.F^{\prime \prime \prime}, G\right)$. The Cuxl analysis confirmed these findings; the number of $\mathrm{Cux}^{+}$neurons generated at E14.5 was also significantly decreased $(40.3 \pm 3.0 \%$ in control cortices and $16.1 \pm 5.0 \%$ in DL-ablated cortices, $\mathrm{Cuxl}^{+} / \mathrm{EdU}^{+}$cells; $p<0.05$; Fig. $\left.9 I-I^{\prime \prime}, J\right)$. Collectively, these results demonstrate that the onset of UL neuron generation is controlled by the termination of DL competence, which is propagated through postmitotic DL neurons. To our knowledge, this study provides the first evidence that progenitor cells use negative feedback cues to regulate the neocortical subtype transition.

\section{Discussion}

In this study, we report that progenitor cells of the cerebral cortex integrate intrinsic (genetic derepression) and extrinsic (negative feedback) cues to produce UL projection neurons at the correct time (Fig. 9K). Although the classical view concerning cortical neurogenesis was that progenitors progressively restrict their competence through successive cell divisions to produce the DL and UL neurons in a fixed order (Frantz and McConnell, 1996; Desai and McConnell, 2000), the lineage relation between DL and UL subtypes has only recently been directly assessed (Yu et al., 2009; Franco et al., 2012; Yu et al., 
2012; Guo et al., 2013). In particular, the presence of ULcommitted progenitors from the earliest phase of corticogenesis has provided an alternative view of cortical neurogenesis (Franco et al., 2012). This finding has left open questions regarding the emergence of UL neurons and the regulation of the timing of their differentiation. Our studies position the emergence of UL progenitors downstream of the Foxg1 gene cascade, in which the onset of Foxg1 switches the transcriptional program to acquire projection neuron identity and, concomitantly, to confer the sequence of DL and UL neurogenesis.

Although the identities of distinct layer subtypes are clearly established through a gene repression network, when the commitment of cell fate occurs during differentiation remains unclear. Of the TFs that compose the laminar subtype network (Fig. $4 A$ ), only Fezf2 has been detected in cortical progenitors (Hirata et al., 2004); others (Tbr1, Ctip2, and Satb2) are only detectable in postmitotic neurons at protein levels (Hevner et al., 2001; Arlotta et al., 2005; Alcamo et al., 2008; Britanova et al., 2008). Consistent with their expression onset after cell cycle exit, Tbr1/Ctip2, Tbr1/ Fezf2, and Ctip2/Satb2 overlap during the initial phase of their expression (Fig. $6 E^{\prime}, E^{\prime \prime}, G^{\prime \prime \prime \prime \prime}, G^{\prime \prime \prime \prime \prime \prime}$; Alcamo et al., 2008). Fezf2 transcription is complexly regulated by a combinatorial activity of multiple enhancers that surround the Fezf2 gene locus that drives its expression independently within the progenitors and DL neurons (Eckler et al., 2014). Because the endogenous Fezf2 mRNA expression in cortical progenitors commences in a caudomedial to rostrolateral gradient (Hirata et al., 2004; Allen Brain Atlas, http://developingmouse.brain-map.org), which is opposite to the Foxg1 expression gradient in the VZ (Kumamoto et al., 2013), Fezf2 activation within progenitors may be independent of Foxg1 regulation. Foxg1 protein expression also exhibits a dynamic expression pattern; its expression is developmentally increased within the progenitor cells, shuts off during migration, and reexpresses during entry into the CP (Fig. 4D-H; Miyoshi and Fishell, 2012). The expression onset of Tbr1 in CP neurons precedes that of Foxg1 (Fig. 4D), which indicates that its transcription is readily activated before Foxg1 expression. Because the Tbr1 protein is not detectable in progenitor cells (Fig. 4D), its expression regulation by Foxg1 is likely mediated in postmitotic neurons after Foxg1 protein upregulation during CP entry in which their expression initially overlaps (Fig. 4E) and later segregates (Fig. $4 F-H$ ). However, because the Tbr1 transcript is significantly decreased within the $\mathrm{CD} 133^{+}$population during Foxg1 induction in vivo (Fig. $4 B, C$ ), we cannot exclude the possibility that Foxg1 also functions in precursor cells to repress its transcriptional activity. Consistent with this view, the onset of Tbr1 protein expression was accelerated within Tuj $1^{+}$early differentiating cells in the Foxg1 E12.5 cKO (Fig. $6 D-D^{\prime \prime \prime}$ ).

Our in vitro assay further suggests that this regulation of Tbr1 expression by Foxg1 is mediated at a transcriptional level (Fig. $4 I, J)$. Importantly, the response of Tbr 1 to Foxg1 induction in vivo is slower compared with the major transcription targets of Foxg1 (Kumamoto et al., 2013). Because these Foxg1-binding sequences are conserved among forkhead-box TFs (Badis et al., 2009), Foxg1 may compete with pre-bound forkhead transcriptional activators to decrease their activity during Foxg1 expression onset. The gain of function of Foxg1 by electroporation driven from a pCAGGS promoter results in a rapid induction of Foxg1 at high levels (Fig. 2D'); thus, the clear switch from Tbr ${ }^{+}$ neurons to Ctip $2 / \mathrm{Fezf}{ }^{+}$neurons in the Foxg1 ${ }^{-/-}$cortex (Fig. 5) may result in the sharp segregation of expression at a shorter time lag compared with the normal developmental situation, in which the Foxg1 protein is expressed at lower and variable levels in progenitors and dynamically regulated during migration and differentiation (Fig. 4D-F; Miyoshi and Fishell, 2012; Kumamoto et al., 2013), which may permit Tbrl expression in a longer temporal window from preplate to layer VI corticothalamic projection neurons. Another possibility is that Foxg1 may trigger multiple independent transcriptional cascades in parallel that converge onto the derepression of Fezf2/Ctip2 expression. In this case, the highly Foxg1-responsive TFs (Kumamoto et al., 2013) may act as repressors of Fezf2/Ctip2 or, alternatively, as activators of Tbr1.

One consideration that concerns the timing of the switch from DL to UL neurogenesis is that, if these transitions rely on feedback signals that are propagated from postmitotic DL neurons, then the transition timings may vary across different clones/ progenies according to the various timings of DL neuron differentiation during development. This consideration is consistent with the finding that, although DL competence is sharply terminated by E14.5 (Fig. $7 E-G^{\prime}$ ), the onset of UL neurogenesis partially overlaps with later DL neurogenesis populations (Takahashi et al., 1999; Hevner et al., 2003). Another interesting possibility that cannot be excluded is that these negative feedback signals may regulate the transition between subcerebral to intracortical projection neuron production rather than DL to UL neurons per se. The current distinction between the DL and UL Satb ${ }^{+}$callosal projection neurons relies on their relative position to the L4 granular cell layer because these neurons share common molecular expression/axon projection patterns; thus, the laminar organization (DL or UL) may be regulated secondary to cell specification $\left(\mathrm{Ctip} 2^{+}\right.$subcerebral projection or Satb2 ${ }^{+}$ intracortical projection) during development.

Our results further suggest that, although some UL progenitors are assigned their fate (Franco et al., 2012) shortly after Foxg1 expression, their differentiation is tightly inhibited in the absence of cues from postmitotic DL neurons. Although the idea of negative feedback signals that regulate neurogenesis has been an attractive hypothesis in both vertebrate and invertebrate CNSs (Taghert et al., 1984; Belliveau and Cepko, 1999), to our knowledge, this study provides the first evidence of negative feedback regulation during subtype transition in the neocortex. Interestingly, this signal appears to act qualitatively rather than quantitatively in vivo. Within the clones that were examined, the numbers of Satb $2^{+}$and Brn $2^{+}$cells did not exceed the number of Ctip ${ }^{+}$cells in the same cluster (Fig. $2 \mathrm{~K}, \mathrm{~S}$ and data not shown). Although the number of UL neurons induced by this approach may be restricted because of the limited competence window of neurogenesis by the late (E14.5) Foxg1 induction, these results demonstrated that only a few postmitotic DL neurons are required to induce UL neurogenesis in this reductionist neocortex model (Fig. 2) compared with the requirements in vitro. This finding raises the possibility that the feedback signals may be propagated through direct cell contact within the clone. Such a short-range feedback system may enhance the precise generation and connectivity between clonally related sister intracortical and subcortical projection neurons (Yu et al., 2009, 2012).

How do these results fit with the alternative lineage-restricted progenitor cell model? Although the fate-mapping studies indicate that both DL and UL lineages are generated downstream of the Foxg1 cascade (Figs. 2, 3A-G) and that UL neurons undergo multiple cell divisions within the Foxg1 lineage (Figs. 2, 3H- $L^{\prime \prime}$ ), these data alone do not distinguish between whether the generation timing differences between the DL and UL neurons is achieved through temporal changes in competence within common progenitors or through extended mitosis specifically in UL-committed cells. Because both common-lineage and 
restricted-lineage models require the termination of DL competence, negative feedback from postmitotic neurons may be the primary source of this cue in both cases, whereas the latter model would require additional mechanisms to extend mitosis in ULcommitted cells. Although the observed decrease in Satb2 ${ }^{+}$and $\mathrm{Cux}^{+}{ }^{+}$cells generated at the expense of extended DL neurogenesis shortly after ablation (Fig. $9 D, G, J$ ) suggests the presence of common progenitors that can contribute to both DL and UL neurons, it is possible that the prolonged DL production as a result of ablation may result in extended proliferative cues for UL cells. This regulation has been observed in Sip $1^{+}$postmitotic neurons that control the expression of $\mathrm{Ntf} 3$; accumulative levels of $\mathrm{Ntf} 3$ are required to induce the differentiation of UL progenitors (Seuntjens et al., 2009). The extended DL neurogenesis achieved through the ablation of DL neurons themselves may sustain low Ntf3 signaling, thereby maintaining the ULcommitted cells as progenitor cells for a prolonged period of time.

Considering the differences in the cell cycle length, gestational period, and neocortical size among different mammals (Arai et al., 2011; Reillo and Borrell, 2012; Betizeau et al., 2013), relying exclusively on an intrinsic transcriptional program appears to be a daunting task to balance neuronal output during development and evolution. The mechanism identified in this study may provide one explanation as to how the timing and number of UL neurons produced are adjusted according to the overall generation of their DL counterparts on a species-specific developmental time scale.

\section{References}

Abdel-Mannan O, Cheung AF, Molnár Z (2008) Evolution of cortical neurogenesis. Brain Res Bull 75:398-404. CrossRef Medline

Aboitiz F, Montiel J (2003) One hundred million years of interhemispheric communication: the history of the corpus callosum. Braz J Med Biol Res 36:409-420. CrossRef Medline

Alcamo EA, Chirivella L, Dautzenberg M, Dobreva G, Fariñas I, Grosschedl R, McConnell SK (2008) Satb2 regulates callosal projection neuron identity in the developing cerebral cortex. Neuron 57:364-377. CrossRef Medline

Arai Y, Pulvers JN, Haffner C, Schilling B, Nüsslein I, Calegari F, Huttner WB (2011) Neural stem and progenitor cells shorten S-phase on commitment to neuron production. Nat Commun 2:154. CrossRef Medline

Arlotta P, Molyneaux BJ, Chen J, Inoue J, Kominami R, Macklis JD (2005) Neuronal subtype-specific genes that control corticospinal motor neuron development in vivo. Neuron 45:207-221. CrossRef Medline

Badis G, Berger MF, Philippakis AA, Talukder S, Gehrke AR, Jaeger SA, Chan ET, Metzler G, Vedenko A, Chen X, Kuznetsov H, Wang CF, Coburn D, Newburger DE, Morris Q, Hughes TR, Bulyk ML (2009) Diversity and complexity in DNA recognition by transcription factors. Science 324: 1720-1723. CrossRef Medline

Balordi F, Fishell G (2007) Mosaic removal of hedgehog signaling in the adult SVZ reveals that the residual wild-type stem cells have a limited capacity for self-renewal. J Neurosci 27:14248-14259. CrossRef Medline

Belliveau MJ, Cepko CL (1999) Extrinsic and intrinsic factors control the genesis of amacrine and cone cells in the rat retina. Development 126: 555-566. Medline

Betizeau M, Cortay V, Patti D, Pfister S, Gautier E, Bellemin-Ménard A, Afanassieff M, Huissoud C, Douglas RJ, Kennedy H, Dehay C (2013) Precursor diversity and complexity of lineage relationships in the outer subventricular zone of the primate. Neuron 80:442-457. CrossRef Medline

Britanova O, de Juan Romero C, Cheung A, Kwan KY, Schwark M, Gyorgy A, Vogel T, Akopov S, Mitkovski M, Agoston D, Sestan N, Molnár Z, Tarabykin V (2008) Satb2 is a postmitotic determinant for upper-layer neuron specification in the neocortex. Neuron 57:378-392. CrossRef Medline

Chen B, Wang SS, Hattox AM, Rayburn H, Nelson SB, McConnell SK (2008) The Fezf2-Ctip2 genetic pathway regulates the fate choice of subcortical projection neurons in the developing cerebral cortex. Proc Natl Acad Sci U S A 105:11382-11387. CrossRef Medline

Desai AR, McConnell SK (2000) Progressive restriction in fate potential by neural progenitors during cerebral cortical development. Development 127:2863-2872. Medline

Eckler MJ, Larkin KA, McKenna WL, Katzman S, Guo C, Roque R, Visel A, Rubenstein JL, Chen B (2014) Multiple conserved regulatory domains promote Fezf2 expression in the developing cerebral cortex. Neural Dev 9:6. CrossRef Medline

Eiraku M, Watanabe K, Matsuo-Takasaki M, Kawada M, Yonemura S, Matsumura M, Wataya T, Nishiyama A, Muguruma K, Sasai Y (2008) Selforganized formation of polarized cortical tissues from ESCs and its active manipulation by extrinsic signals. Cell Stem Cell 3:519-532. CrossRef Medline

Espuny-Camacho I, Michelsen KA, Gall D, Linaro D, Hasche A, Bonnefont J, Bali C, Orduz D, Bilheu A, Herpoel A, Lambert N, Gaspard N, Péron S, Schiffmann SN, Giugliano M, Gaillard A, Vanderhaeghen P (2013) Pyramidal neurons derived from human pluripotent stem cells integrate efficiently into mouse brain circuits in vivo. Neuron 77:440-456. CrossRef Medline

Fietz SA, Huttner WB (2011) Cortical progenitor expansion, self-renewal and neurogenesis-a polarized perspective. Curr Opin Neurobiol 21:2335. CrossRef Medline

Franco SJ, Gil-Sanz C, Martinez-Garay I, Espinosa A, Harkins-Perry SR, Ramos C, Müller U (2012) Fate-restricted neural progenitors in the mammalian cerebral cortex. Science 337:746-749. CrossRef Medline

Frantz GD, McConnell SK (1996) Restriction of late cerebral cortical progenitors to an upper-layer fate. Neuron 17:55-61. CrossRef Medline

Gaspard N, Bouschet T, Hourez R, Dimidschstein J, Naeije G, van den Ameele J, Espuny-Camacho I, Herpoel A, Passante L, Schiffmann SN, Gaillard A, Vanderhaeghen P (2008) An intrinsic mechanism of corticogenesis from embryonic stem cells. Nature 455:351-357. CrossRef Medline

Guo C, Eckler MJ, McKenna WL, McKinsey GL, Rubenstein JL, Chen B (2013) Fezf2 expression identifies a multipotent progenitor for neocortical projection neurons, astrocytes, and oligodendrocytes. Neuron 80: 1167-1174. CrossRef Medline

Hanashima C, Shen L, Li SC, Lai E (2002) Brain factor-1 controls the proliferation and differentiation of neocortical progenitor cells through independent mechanisms. J Neurosci 22:6526-6536. Medline

Hanashima C, Li SC, Shen L, Lai E, Fishell G (2004) Foxgl suppresses early cortical cell fate. Science 303:56-59. CrossRef Medline

Han W, Kwan KY, Shim S, Lam MM, Shin Y, Xu X, Zhu Y, Li M, Sestan N (2011) TBR1 directly represses Fezf2 to control the laminar origin and development of the corticospinal tract. Proc Natl Acad Sci U S A 108: 3041-3046. CrossRef Medline

Hansen DV, Lui JH, Parker PR, Kriegstein AR (2010) Neurogenic radial glia in the outer subventricular zone of human neocortex. Nature 464:554561. CrossRef Medline

Hevner RF, Shi L, Justice N, Hsueh Y, Sheng M, Smiga S, Bulfone A, Goffinet AM, Campagnoni AT, Rubenstein JL (2001) Tbrl regulates differentiation of the preplate and layer 6. Neuron 29:353-366. CrossRef Medline

Hevner RF, Daza RA, Rubenstein JL, Stunnenberg H, Olavarria JF, Englund C (2003) Beyond laminar fate: toward a molecular classification of cortical projection/pyramidal neurons. Dev Neurosci 25:139-151. CrossRef Medline

Hirata T, Suda Y, Nakao K, Narimatsu M, Hirano T, Hibi M (2004) Zinc finger gene fez-like functions in the formation of subplate neurons and thalamocortical axons. Dev Dyn 230:546-556. CrossRef Medline

Ivanova A, Signore M, Caro N, Greene ND, Copp AJ, Martinez-Barbera JP (2005) In vivo genetic ablation by Cre-mediated expression of diphtheria toxin fragment A. Genesis 43:129-135. CrossRef Medline

Kadoshima T, Sakaguchi H, Nakano T, Soen M, Ando S, Eiraku M, Sasai Y (2013) Self-organization of axial polarity, inside-out layer pattern, and species-specific progenitor dynamics in human ES cell-derived neocortex. Proc Natl Acad Sci U S A 110:20284-20289. CrossRef Medline

Kumamoto T, Toma K, Gunadi, McKenna WL, Kasukawa T, Katzman S, Chen B, Hanashima C (2013) Foxgl coordinates the switch from nonradially to radially migrating glutamatergic subtypes in the neocortex through spatiotemporal repression. Cell Rep 3:931-945. CrossRef Medline

Kwan KY, Lam MM, Krsnik Z, Kawasawa YI, Lefebvre V, Sestan N (2008) SOX5 postmitotically regulates migration, postmigratory differentiation, 
and projections of subplate and deep-layer neocortical neurons. Proc Natl Acad Sci U S A 105:16021-16026. CrossRef Medline

Lui JH, Hansen DV, Kriegstein AR (2011) Development and evolution of the human neocortex. Cell 146:18-36. CrossRef Medline

Madisen L, Zwingman TA, Sunkin SM, Oh SW, Zariwala HA, Gu H, Ng LL, Palmiter RD, Hawrylycz MJ, Jones AR, Lein ES, Zeng H (2010) A robust and high-throughput Cre reporting and characterization system for the whole mouse brain. Nat Neurosci 13:133-140. CrossRef Medline

McKenna WL, Betancourt J, Larkin KA, Abrams B, Guo C, Rubenstein JL, Chen B (2011) Tbr1 and Fezf2 regulate alternate corticofugal neuronal identities during neocortical development. J Neurosci 31:549-564. CrossRef Medline

Miyata T, Kawaguchi A, Okano H, Ogawa M (2001) Asymmetric inheritance of radial glial fibers by cortical neurons. Neuron 31:727-741. CrossRef Medline

Miyoshi G, Fishell G (2012) Dynamic FoxG1 expression coordinates the integration of multipolar pyramidal neuron precursors into the cortical plate. Neuron 74:1045-1058. CrossRef Medline

Nieto M, Monuki ES, Tang H, Imitola J, Haubst N, Khoury SJ, Cunningham J, Gotz M, Walsh CA (2004) Expression of Cux-1 and Cux-2 in the subventricular zone and upper layers II-IV of the cerebral cortex. J Comp Neurol 479:168-180. CrossRef Medline

Niwa H, Yamamura K, Miyazaki J (1991) Efficient selection for highexpression transfectants with a novel eukaryotic vector. Gene 108:193199. CrossRef Medline

Reillo I, Borrell V (2012) Germinal zones in the developing cerebral cortex of ferret: ontogeny, cell cycle kinetics, and diversity of progenitors. Cereb Cortex 22:2039-2054. CrossRef Medline

Schoenemann PT, Sheehan MJ, Glotzer LD (2005) Prefrontal white matter volume is disproportionately larger in humans than in other primates. Nat Neurosci 8:242-252. CrossRef Medline

Seuntjens E, Nityanandam A, Miquelajauregui A, Debruyn J, Stryjewska A, Goebbels S, Nave KA, Huylebroeck D, Tarabykin V (2009) Sip1 regulates sequential fate decisions by feedback signaling from postmitotic neurons to progenitors. Nat Neurosci 12:1373-1380. CrossRef Medline

Shen Q, Wang Y, Dimos JT, Fasano CA, Phoenix TN, Lemischka IR, Ivanova NB, Stifani S, Morrisey EE, Temple S (2006) The timing of cortical neurogenesis is encoded within lineages of individual progenitor cells. Nat Neurosci 9:743-751. CrossRef Medline
Shi Y, Kirwan P, Smith J, Robinson HP, Livesey FJ (2012) Human cerebral cortex development from pluripotent stem cells to functional excitatory synapses. Nat Neurosci 15:477-486, S1. CrossRef Medline

Soriano P (1999) Generalized lacZ expression with the ROSA26 Cre reporter strain. Nat Genet 21:70-71. CrossRef Medline

Srinivasan K, Leone DP, Bateson RK, Dobreva G, Kohwi Y, KohwiShigematsu T, Grosschedl R, McConnell SK (2012) A network of genetic repression and derepression specifies projection fates in the developing neocortex. Proc Natl Acad Sci U S A 109:19071-19078. CrossRef Medline

Srinivas S, Watanabe T, Lin CS, William CM, Tanabe Y, Jessell TM, Costantini F (2001) Cre reporter strains produced by targeted insertion of EYFP and ECFP into the ROSA26 locus. BMC Dev Biol 1:4. CrossRef Medline

Striedter G (2005) Principles of brain evolution. Sunderland, MA: Sinauer.

Taghert PH, Doe CQ, Goodman CS (1984) Cell determination and regulation during development of neuroblasts and neurones in grasshopper embryo. Nature 307:163-165. CrossRef Medline

Takahashi T, Goto T, Miyama S, Nowakowski RS, Caviness VS Jr (1999) Sequence of neuron origin and neocortical laminar fate: relation to cell cycle of origin in the developing murine cerebral wall. J Neurosci 19: 10357-10371. Medline

Tao W, Lai E (1992) Telencephalon-restricted expression of BF-1, a new member of the HNF-3/fork head gene family, in the developing rat brain. Neuron 8:957-966. CrossRef Medline

Xuan S, Baptista CA, Balas G, Tao W, Soares VC, Lai E (1995) Winged helix transcription factor BF-1 is essential for the development of the cerebral hemispheres. Neuron 14:1141-1152. CrossRef Medline

Yu YC, Bultje RS, Wang X, Shi SH (2009) Specific synapses develop preferentially among sister excitatory neurons in the neocortex. Nature 458: 501-504. CrossRef Medline

Yu YC, He S, Chen S, Fu Y, Brown KN, Yao XH, Ma J, Gao KP, Sosinsky GE, Huang K, Shi SH (2012) Preferential electrical coupling regulates neocortical lineage-dependent microcircuit assembly. Nature 486:113-117. CrossRef Medline

Zirlinger M, Lo L, McMahon J, McMahon AP, Anderson DJ (2002) Transient expression of the bHLH factor neurogenin-2 marks a subpopulation of neural crest cells biased for a sensory but not a neuronal fate. Proc Natl Acad Sci U S A 99:8084-8089. CrossRef Medline 